\title{
Financial Integration of Emerging Markets: An Analysis of Latin America Versus South Asia Using Individual Stocks*
}

\author{
Cathy S. Goldberg \\ University of San Francisco, U.S.A. \\ Francisco A. Delgado \\ UBS Warburg, U.S.A.
}

\begin{abstract}
This article presents an analysis of financial integration for emerging financial markets. The results indicate that for the sample of countries examined, Argentina, Chile, Mexico and Thailand's stock markets are financially integrated. Conclusions are reached by first identifying endogeonous breaks in multiple stock return series and then constructing confidence intervals around these break dates. Further support is provided that identified breaks are due to integration by performing statistical analyses on the return series pre and post break. In general, the stocks in integrated countries become more correlated with world and industry indexes. Mean returns for these stocks decrease and become more aligned with the mean returns of their respective industry indexes. In cases where we do not find supporting evidence for financial integration, the break dates correspond to currency crises or other events that caused a shift in the return series (JEL G15, G12).
\end{abstract}

Keywords: emerging markets, financial integration, structural break tests.

\section{Introduction}

What is meant by the phrase "financial integration in capital markets"? Simply defined, if financial markets are integrated, financial assets traded in different markets, but with related risk characteristics will have similar expected returns. A country's stock market can move from a segmented regime to an integrated one as various liberalization events

*The authors are grateful to three anonymous referees for helpful comments on an earlier draft of this article. The usual disclaimer applies.

(Multinational Finance Journal, 2001, vol. 5, no. 4, pp. 259-301)

CMultinational Finance Society, a nonprofit corporation. All rights reserved.

DOI: $10.17578 / 5-4-2$ 
occur: often the relaxation of government restrictions on foreign participation in their equity markets facilitates this transition. In the absence of loosening investment policies, other vehicles do exist which allow foreign investment in equity markets (i.e. country funds and ADR's).

Recently, dating the integration of emerging equity markets has been receiving greater attention in the finance literature (see Bekaert, Harvey, and Lumsdaine [2001]). Emerging equity markets have continued to grow due in part to the changing laws governing foreign investment in these markets. During the last decade, there has also been a dramatic increase in the issuance of American Depository Receipts (ADR's) or General Depository Receipts (GDR's) that allow trade of foreign securities on the NYSE or on non-American exchanges. One would expect these and other liberalization events to have some impact on the pricing of a country's securities and thus, potentially contribute to the integration process in the emerging market. However, it would be incorrect to presuppose that regime switches occur at a known liberalization event date. Even when governments institute a policy to open stock markets to foreigners, the desired effect of increased foreign participation may not occur and thus, the market will remain segmented. Therefore, the ability to accurately date when switches in security pricing regimes occur requires a formalized statistical model. The notion of dating financial integration ${ }^{1}$ should be of great interest to practitioners, governments and academics. For these individuals, the subject areas in which the dating issue is relevant include portfolio management, economic policy, corporate investment policy, and asset pricing research. For instance, a government who institutes legislation to reduce barriers to foreign investment may wish to know if this legislation has been successful in achieving its goals. An academic performing studies on the cost of capital for emerging markets will need to use valid periods of estimation which do not cross the time when markets switch from a segmented to an integrated regime. These particular examples highlight the need to develop and utilize econometric techniques for dating the integration of emerging markets to the global financial markets.

1. Dating financial integration in this article refers to identifying the period where stock market returns behave similarly to global markets. First a break in the return process is identified and then statistical evidence is provided to confirm that the break is due to financial integration. 
By examining stock market variables in emerging economies, particularly the return generating process, much can be learned with respect to the dating of financial integration of these countries' stock markets. As emerging markets move from a segmented to an integrated regime, one would expect stock returns to be impacted by the liberalization process, mostly because of changing risk characteristics in the emerging market stocks. In order to test for a change in the return process, one could construct a test that specifies a null hypothesis of no structural break $^{2}$ in a regime versus the alternative of an unknown structural break. Specifically, such a test could examine breaks in a stock's return series through time. The necessary (but not sufficient) condition for concluding that capital markets have integrated would be the detection of a structural break in the specified model of returns. If we fail to reject the null hypothesis of no structural break in the stock return generating process, then we must conclude that the stock markets have not integrated. Once a break is detected, the next step is to examine what changes occur in the time series post identified break date. The intuition about the effects of financial market integration can then be statistically tested in order to confirm that the break identified was caused by market integration.

In this study, stock return data is obtained from the Emerging Markets Data Base (EMDB) compiled by the International Finance Corporation (IFC). This study attempts to date the financial integration of eight emerging equity markets in Latin America and South Asia to world equity markets. The analysis uses the econometric methods developed by Bai, Lumsdaine, and Stock 1998 (BLS [1998]) to identify a single break in multiple time series. A VAR system of autoregressive equations for each country's stocks is developed in order to identify breaks in each country and construct confidence intervals for each break. Our contributions to the literature are along the following lines: past studies using these methods have relied on country indexes, which change from year to year. ${ }^{3}$ Additionally, these studies only use one financial series or modifications of the price index series for any given

2. A structural break can be defined as a change in the coefficients on the dependent variables in a model, tested at a specific point in the sample under consideration.

3. See IFC Index Report (1999) for a detailed description of country index composition. 
country. Confidence intervals are reduced by adding macro time series or by combining the return series with the dividend yield or a trading volume measure. Often, confidence interval endpoints derived from a single series lie completely outside the sample data period. The power of the BLS (1998) method lies in the narrowing of the confidence interval when adding additional time series to the VAR system-thus providing a more informative statistic for the identification of break dates. In addition, the methodology is designed to work with series that share a common break. It seems logical that using return series for individual stocks from the same country should do well in identifying such a break. By using the return series of stocks within a given country, this study may be able to identify this common break attributable to financial integration more accurately. In order to further corroborate the article's findings, a VAR analysis on the larger stocks will be run within each country. Interest in the larger stocks returns (i.e. larger market capitalization) is that these are the stocks that are more frequently traded and of more interest to developed country portfolio managers.

Another major contribution will be the linking of the break dates identified to: (1) actual liberalization events in a country and (2) relevant statistics which are indicative of integration. In order to accomplish the former, an attempt will be made to place the identified break date within the timeline of the emerging market's political, economic and financial liberalization events over the period of the study. The latter will be addressed by looking at relevant statistics pre and post break date and will include: (a) differences in mean returns for the individual stocks; (b) differences in mean returns of the stocks versus the mean returns of their world industry index; (c) regression coefficients (betas) of the individual stocks against the Morgan Stanley World Index (MSWI); (d) betas with the Standard and Poor's 500 (S\&P500) and (e) betas with a stock's industry index. ${ }^{4}$

Post financial integration, one would expect mean stock returns to decrease. ${ }^{5}$ Intuitively, this should happen because of increased demand in the emerging stock market as well as, risk sharing benefits, both of which would drive returns downwards. Betas with world indicators

4. World industry indexes are provided by the data used in Fama and French (1997).

5. Domowitz, Glen, and Madhavan (1997) show this is true for Mexican stocks with different trading classes. 
should increase if the stock markets of our emerging economies do financially integrate at or around the identified break date ( i.e., their returns post break should move more closely with the US and world indicators). ${ }^{6}$ Financial integration implies that an individual stock's mean return would become more aligned with the mean return of its respective industry index. The econometrics of constructing tests pre and post break date on these statistics will be discussed in greater detail in section III of this article.

The countries in this study have been prone to large swings in exchange rates due in large part to local crises during the last 2 decades. ${ }^{7}$ Therefore, local currency data will be used in order to avoid identifying a break in stock returns that may actually be the result of the exchange rate present in all individual stock returns if the stock prices are denominated in US dollars. The IFC derives its US equivalent returns by using the spot exchange rate to convert local currency returns. Because of this, there are two potential drawbacks to using USD returns. The first is that additional noise is introduced into the return series that may mask a break due to financial integration. Second, if a break is detected in the return series that is identified using USD returns, one may actually be capturing extreme movement in exchange rates and not a switch in the country's pricing mechanism for stocks. From a practitioner's standpoint, USD returns can be decomposed into 2 elements: the local return component and the exchange rate component. Forwards and futures markets are available to hedge the currency risk element. However, there is no natural hedge for the local return portion and so this part becomes the only matter of importance in pricing a security in the emerging market. Thus, breaks induced by the segmentation/integration process are better identified when using only the local returns portion of the time series under investigation. One caveat is that a local currency crises may still impact returns, independent of the exchange rate fluctuation. However, this study avoids the additional noise that is most pronounced in the exchange rate series by not incorporating it into the analysis. We contend that past

6. Bekaert, Harvey, and Lumsdaine (2001) find that the index returns for their countries are more correlated with world returns post integration.

7. For example, Brazil has gone through various currency reforms that followed inflationary crises caused by permanent government deficits. 
studies, in particular Bekaert, Harvey, and Lumsdaine (2001), could have identified different or insignificant dates using USD returns instead of local currency returns.

We hope to accomplish the following in this study: (1) identify significant break dates for emerging market countries, which differ from past studies due to the use of individual stock returns and local currency returns; (2) construct meaningful confidence intervals using multiple stock series; (3) examine the behavior of mean stock returns pre and post break; (4) further link the break date to financial integration by examining individual stock betas with respect to the MSWI, S\&P500 and industry indexes pre and post break; and (5) corroborate the break date findings by comparing them to actual liberalization events which occurred in this study's sample of emerging market economies.

This article proceeds as follows: section II outlines the relevant literature in the field. In section III, we discuss the data and methodology used in this study. Section IV provides a detailed analysis of our results for our sample of Latin American and South Asian countries. Conclusions and a discussion of areas for further research are presented in section $\mathrm{V}$.

\section{Literature}

The literature on economic and financial market integration can be divided into two areas. The first area develops the notion of integration in conjunction with a particular asset-pricing model or pricing kernel. The main idea here is to postulate that assets which exhibit related risk characteristics should yield similar returns. The following articles test the integration of capital markets by considering the returns of assets of similar risks: Errunza and Losq (1985), Campbell and Hamao (1992), Mittoo (1992), and Ammer and Mei (1996). These studies develop adhoc models to test this hypothesis, utilizing both macro-economic and financial variables.

The technology we use in identifying breaks has its foundations in the second area of the literature. This literature begins with empirical studies related to regime breaks: specifically exploring the existence or lack thereof of unit roots in macroeconomic data. These studies focus on changing slope (or intercept) coefficients in the specific functions 
examined. Perron (1989) and Rappaport and Reichlin (1989) both explore the implications of a regime change based on regressions of macroeconomic data at a "known" date. Banarjee, Lumsdaine, and Stock (1992), Hansen (1992), Andrews (1993) and Andrews, Lee, and Ploberger (1996) explore structural changes in economic testing with an unknown change point. Finally, Bai, Lumsdaine, and Stock (1998) extend the research to developing confidence intervals for a single break date in multivariate time series. Bekaert, Harvey, and Lumsdaine (2001) identify potential integration dates for the countries represented in the Emerging Markets Database (EMDB) by using the above stated technology. They utilize the indexes for the countries and examine total returns, as well as dividend yields and other financial variables reported in the database. Their means of achieving multiple series systems is to couple the index financial variable with world instruments. They also examine the implications of potential integration on returns, dividend yields and credit ratings post break date. This study utilizes the above mentioned techniques to examine financial integration on a stock-bystock basis and VAR combinations of multiple stock return series for a given country. As previously discussed, using return series for individual stocks rather than adding macro economic series may lead to different breaks in some cases which are indicative of the financial integration periods for our sample of emerging market countries. A comparison of break dates where significant differences are found is provided in section IV, where country results are highlighted.

\section{Data and Methodology}

We chose the countries in this study by using the IFC regional groupings (Latin America and South Asia) because there are more differences across regions than within regions. Even though these emerging economies liberalized within the last ten years, they have tended to follow regional trends and policies in their liberalization and integration policies. Other Latin American and Asian countries are included in the IFC database, however they are either included in other regions of the IFC classification or contained insufficient datasets for this particular study.

Individual stocks for each country were selected based on a tradeoff 
between (1) market capitalization and (2) available trading history. Since many of the stock market liberalization events occurred in the late 1980's/early 1990's, enough trading data was required for the selected stocks in order to run the VAR analysis. Although this did require some qualitative judgement based on what trading period was sufficient, the choices of individual stocks for each country do contain the larger stocks for that country. It is likely that these larger and more frequently traded stocks will exhibit the breaks in the return generating process, which is the necessary condition for financial integration to occur. Market capitalization for each stock and trading period for each country are reported in table 1 for Latin America and table 4 for South Asia.

Specifically, total returns were examined for 8 emerging market countries in Latin America and South Asia categories as reported by the IFC for the period 1975/12-1999/09. Past studies have considered U.S. dollar total returns for country indexes. Instead, this study utilizes the returns for individual stocks in local currency. An explanation for using local currency returns is provided in the introduction of this article.

Utilizing the methodology developed by BLS (1998) ${ }^{8}$, a country-bycountry stock analysis is performed in order to: (i) identify break dates in the market regime and (ii) construct confidence intervals for these break dates. Subsequently, (iii) results are corroborated by calculating beta coefficients between the returns for stocks against various world indexes as well as, by examining changes in mean returns for these stocks pre and post break date. The following VAR system of equations is considered:

$$
y_{t}=\mu+\sum_{j=1}^{p} A_{j} y_{t-j}+\Gamma X_{t-1}+d_{t}(k)\left(\lambda+\sum_{j=1}^{p} B_{j} y_{t-j}+\Pi X_{t-1}\right)+\varepsilon_{t},
$$

where $y_{t}, \mu, \lambda$ and $\varepsilon_{t}$ are $n \times 1, A_{j}$ and $B_{j}$ are $n \times n$ and $d_{t}(k)=0$ for $t$ $\leq k$ and $d_{t}(k)=1$ for $t>k$. $k$ is the stated "break" date, $X_{t}$ represents an exogenous variable that in our case will be the Morgan Stanley World Index (MSWI).

In order to run the VAR analysis, the appropriate lag length is identified (testing 0 to 6 lags) in the VAR systems for each country's

8. All equations are taken directly from BLS (1998). 
stocks. This should be an adequate range to capture any lagged effects in the VAR system. Any lag length greater than 6 would probably consume degrees of freedom unnecessarily as historical information greater than 6 months old would not improve the fit of the model. ${ }^{9}$ Using the criterion developed by Sims (1980), the following statistic is maximized:

$$
\lambda=T\left(\ln |S|-\ln \left|S^{*}\right|\right)
$$

where $S$ is the $n \times n$ residual covariance matrix based on lag length $p$ and $S^{*}$ is its counterpart for $p+1$ lags. The statistic has a chi-squared distribution with $n^{2}$ degrees of freedom. The test is one in which we keep adding lags until the last parameter matrix does not lead to a significant improvement in the fit.

Following BLS (1998), a sequence of Wald statistics is developed for each $k=k^{*}+1, \ldots, T-k^{*}$ where $k^{*}$ is a $15 \%$ trimming value of the sample $T .{ }^{10}$ For any given $k$, the estimators of $\hat{B}(k)$ and $\hat{F}(k)$ testing $S \delta=$ 0 , are: ${ }^{11}$

$$
\begin{gathered}
\hat{B}(k)=\left\{\sum_{t=1}^{T}\left(Z_{t} \hat{\Sigma}_{k}^{-1} Z_{t}^{\prime}\right)\right\}^{-1} \sum_{t=1}^{T} Z_{t} \hat{\Sigma}_{k}^{-1} y_{t}, \\
\hat{F}(k)=T\{R \hat{B}(k)\}^{\prime}\left\{R\left(T^{-1} \sum_{t=1}^{t} Z_{t} \hat{\Sigma}_{k}^{-1} Z_{t}^{\prime}\right)^{-1} R^{\prime}\right\}^{-1}\{R \hat{B}(k)\},
\end{gathered}
$$

where $R=(0, I)$ or $R B=S \delta$ and $\hat{\Sigma}_{k}$ is the $\Sigma$ obtained from OLS residuals under the alternative hypothesis given $k{ }^{12}$ Based on the

9. In our empirical implementation we do not find lags higher than 6 .

10. The trimming is the reduction of the sample size at the beginning and end of the sample to guarantee non-singular matrixes.

11. This tests whether or not a change has occurred on the coefficients of the variables used in the VAR system, i.e., does a structural break occur in the system for any given month $(k)$ in the sample period.

12. $\hat{F}(k)$ represents the Wald test statistics derived from using our data at each month 
sequence of statistics obtained in the previous step, one would choose the maximum $F_{t}$ process, or the maximum Wald statistic. BLS (1998) show that $F_{t}(k)$ has the following limiting distribution: ${ }^{13}$

$$
F^{*}(\tau)=\{\tau(1-\tau)\}^{-1}(W(\tau)-\tau W(1))^{2}
$$

for $\tau \varepsilon(0,1)$, where $W$ is a standard Brownian motion process and $\tau=\hat{k} / T$. It is shown that since max is a continuous function, BLS (1998) derive $\max _{k} F_{T} \Rightarrow \operatorname{SupF}(\tau)$. The $\hat{k}$ that maximizes $F_{T}(k)$ is the estimated break date. The test is called the Sup-Wald test. Critical values are obtained using 2000 Monte Carlo simulations with a discretization grid of 5000. This is a discrete approximation to the limiting distribution of $F^{*}$. The dimension $q$ in appendix A is equivalent to the dimension of $S \delta$ in $F_{T}(k)$. One can use this table to compare the max $F_{T}$ (k) statistic and thus test for significance at the $10 \%, 5 \%$ and $1 \%$ levels. ${ }^{14}$ Using the derivation of BLS (1998, theorem 4) confidence intervals can be constructed for the breakpoint by:

$$
\hat{k} \pm \alpha_{i / 2 \pi}\left[\left(S \hat{\delta}_{T}\right)^{\prime} S\left(\hat{Q} \otimes \hat{\Sigma}_{\hat{k}}^{-1}\right) S^{\prime}\left(S \hat{\delta}_{T}\right)\right]^{-1}
$$

where

$$
\hat{Q}=1 / T \sum_{t=1}^{T} V_{t} V_{t}^{\prime}
$$

and $\alpha_{1 / 2 \pi}=4.67$ and 7.63 for $90^{\text {th }}$ and $95^{\text {th }}$ percentiles respectively. ${ }^{15,16}$

represented by tau. It is the statistic used to test the hypothesis $S \delta=0$, incorporating the estimates of the $\hat{B}(k)$ (coefficients from the VAR analysis) and $\hat{\Sigma}_{k}$ is the covariance matrix of the error terms.

13. See theorem 1 in BLS (1998) for proof.

14. Similar values using this Monte Carlo approach can be found in Bekaert, Harvey, and Lumsdaine (2001).

15. $V_{t}=\left(1, y_{t-1}, \ldots, y_{t-p}, X_{t-1}\right)$ where the $y$ variables represent the lags of the stock returns in the VAR and $X$ represents the MSWI.

16. Picard (1985) provides a proof of the limiting distribution of $V^{*}$ and derives these 
We postulate that the larger stocks within a country may be more apt to result in a break due to foreign investor interest. Thus, the VAR system is run on the largest 3 and 5 market capitalization stocks within each country, and on all stocks in the country in order to test for significance and improvement in interval width. It should be noted that we do not form portfolios of these stocks but instead, use the econometric technology mentioned to run each stock series in a multivariate system.

\section{Support for integration}

We provide support for our break date results in several ways. First, we observe where our break date falls in the sequence of liberalization events for a specific country and judge the feasibility of its place in the timeline and integration occurring at that date. Next, a series of regressions of the stock returns on various world indexes is performed. A test is constructed to see if the covariance of the countries' stock returns increases with the world indicator indexes as proxied by the MSWI, S\&P500 and industry indexes compiled by Fama and French (1997). The following Wald statistic is constructed which tests for a significant difference in the betas pre and post break date:

$$
W=\left(B_{\text {pre }}-B_{\text {post }}\right)\left(V_{\text {pre }}+V_{\text {post }}\right)^{-1}\left(B_{\text {pre }}-B_{\text {post }}\right)
$$

where $W$ is distributed chi-squared with one degree of freedom, $B$ represents the regression coefficient of the stock return on the MSWI, S\&P500 or industry index and $V$ represents the White variancecovariance matrix of the estimated coefficients adjusted for heteroscedasticity. Our prior is that post financial integration, we should see an increase in the beta coefficients with respect to the MSWI, S\&P500 and industry indexes. The reasoning is quite simple-if the stocks of our emerging economies do financially integrate at or around the identified break date, their return post break should move more closely with the US and world indicators. A stock in a particular industry would be expected to move more closely with the overall industry index.

values. 
In addition, an analysis is performed on the mean stock returns pre and post break date (disregarding 3 months on either side of the break date). Past research has shown that when foreign investors are allowed to purchase emerging market stocks, these stocks experience a decrease in returns (see Domowitz, Glen, and Madhavan [1997]). One explanation for this is that the price of the stock is bid up at that time by the increased demand and thus the overall yield is less. Another argument is that the risk sharing that occurs once foreigners add these stocks to their portfolios decreases the risk of holding that stock and hence decreases the return as well.

Financial integration implies that stocks within a particular industry exhibit similar risk characteristics to the industry benchmark, hence yield similar returns. This study uses the world industry indexes constructed by Fama and French (1997) and compares a specific industry index return with the returns of corresponding stocks in the emerging market countries pre and post break date. We expect to see a significant difference pre break and no difference post break if markets are financially integrated. In order to test for significant differences, the following test statistic is constructed:

$$
z^{*}=(\bar{y}-\bar{x}) / s(\bar{y}-\bar{x})
$$

where $\bar{y}$ and $\bar{x}$ represent the mean returns of the stock and industry index respectively. The difference is computed for both pre and post break date returns and follows a standard normal distribution.

\section{Results}

\section{A. Latin America}

The countries included in this analysis are Argentina, Brazil, Chile and Mexico. Other Latin American countries covered in the database did not have sufficient data or large enough stock markets in order for our econometric techniques to work properly. Except for Brazil, all other countries in the Latin American sample show strong evidence of financial integration. 


\section{Argentina}

Eleven stocks were examined for which data were available from December 1984 to September 1999. The majority of these stocks break at or around June 1989. In addition, the largest 7 stocks all exhibit the same June 1989 break (i.e. those stocks which are traded more actively). For individual stocks the breaks are significant at the $1 \%$ level (see table 1A). When the VAR system is run for the largest 3 and 5 stocks, the individual stock findings are confirmed and the confidence intervals are narrowed. Both systems of equations lead to the same June 1989 break, significant at the $1 \%$ level. When the system is run with all 11 stocks, a slightly later break date is found but this break is only significant at the $10 \%$ level. This may be attributed to the introduction of the smaller stocks in the VAR system that break at a later date (i.e., potential outliers in the sample due to smaller market capitalization).

The timeline for Argentina would seem to support the mid 1989 break as one that occurred due to financial integration. The Argentine government's commitment to economic reforms began in 1988 and included liberalizing trade and an aggressive privatization program. Legislation introduced in November 1989 essentially removed all barriers to foreign stock market investment. Any one vehicle or combination of these occurrences can lead to a switch in the pricing regime of an emerging country's stocks.

Tables 2 and 3 provide strong evidence that the breaks found for Argentina are indeed indicative of financial integration. Table $2 \mathrm{~A}$ shows that the mean returns for all 11 stocks decrease significantly post-break. With respect to both the S\&P 500 and the MSWI, almost all the stocks in the sample exhibit significant increases in beta coefficients post-break (see table 3A). We do not report industry return results however, the differences between the stocks' returns and their corresponding industry returns is statistically different from zero pre-break. Post break this difference vanishes. For the largest 5 stocks, findings indicate that stock returns move more closely with their industry returns post-break and these regression coefficients are significant at the 5\% level.

\section{Brazil}

We selected 10 of Brazil's stocks for the period May 1987 to November 1996. The results obtained are challenging to analyze. First, the break dates obtained in table $1 \mathrm{~B}$ vary from stock to stock. These differences increase for the different groupings, bringing into question the existence 
of a unique break and the occurrence of financial integration. The break dates seem to coincide with currency reforms introduced in late 1993 and mid 1994. These reforms were introduced following the inflationary crises caused by the permanent government deficits. Liberalization events in Brazil occurred somewhat earlier, particularly major reforms to foreign investment law, which were introduced in mid 1991.

Past studies have dated integration in mid 1991 (for example, Bekaert, Harvey, and Lumsdaine [2001]) however we do not find evidence to support this claim. Although not reported in the tables, we run separate analyses for this break date and find no support for change in mean returns nor increases in correlation coefficients. The mid 1994 break date results reported are biased due to insufficient observations and large negative returns post break. Thus, we find that the results obtained for Brazil are inconclusive.

\section{Chile}

Eleven stocks are examined for which data are available from December 1975 to October 1998 (see table 1C). Except for stock 6, the other stocks seem to break in early to mid 1980 with $90 \%$ confidence intervals ranging from under one year on either side to 2 years. Ten of the 11 stocks have significant break dates at the $1 \%$ level of confidence.

Significant results are obtained when we combine the 3 and 5 largest stocks in the sample. The top 3 market capitalization stocks appear to break in 1980 with a midpoint of May 1980. The interval is 5 months on either side of this date. This result is significant at the $1 \%$ level. Results obtained for the 5 largest stocks at the $90 \%$ interval are also significant at the $1 \%$ level. The interval is narrowed to 3 months on either side, however the midpoint is a few months earlier (January 1980). Using all 11 stocks in the VAR system improves the interval to 1 month for both the $90 \%$ and $95 \%$ intervals, however produces a slightly different interval due to an earlier break date of July 1979. Chile's stock index in both local and US currency appears to break in 1980 as well, with a midpoint of July 1980 for both cases (see table 1C). However, the result for the index in local currency produces tighter confidence bands than the country index in USD.

Chile is an interesting country to analyze as its focus with respect to economic and financial liberalization preceded any of its Latin America partners, occurring in the late 1970's and throughout the 1980's. 
"The most difficult, controversial, and costly reforms-including the bulk of privatization, trade liberalization, financial deregulation, and major market streamlining were undertaken in Chile in the 1975-1980 period; the measures taken after 1985 were minor, in comparison. The success of the post 1985 period was rooted in the earlier reforms." 17

The IFC declared the market open in late 1988 and the investment vehicles such as the country fund and ADR did not exist until 1989 and 1990 respectively. However, during the Pinochet regime, any barrier to foreign investment was virtually eliminated and by late 1979 to early 1980, foreigners had access to Chilean companies through unrestricted direct investment and Decree Law 600. Taking these events into consideration, a break date in the early 1980's is both reasonable and highly likely. Certainly our results for individual and groups of stocks in the VAR system support this period of integration.

Table 2C provides strong support that our break date is indicative of financial integration. All stocks show that the mean returns decrease significantly at the 5\% level post-break. Except for CGE, which may be mismatched with the Fama French industry indexes, the results show differences in mean returns between the stocks and their industries prebreak and no difference post-break.

Bekaert, Harvey, and Lumsdaine (2001) date Chile's integration into world markets around early 1992. We obtain results that indicate financial integration occurred much earlier (1980). Given our strong break date results, supporting statistics and the liberalization events of Chile discussed above, we contend that Chile's financial markets did financially integrate at our reported break date.

Mexico

The official liberalization date by the IFC and the ADR introduction for Mexico both occur in mid-1989, as well as break dates reported in previous studies (Bekaert, Harvey, and Lumsdaine [2001], Buckberg [1995]). However, this study's break date and resulting confidence intervals for the largest 3 and 5 stocks as well as all 11 stocks in the VAR occurred around June 1987. The confidence intervals for these

17. Library of Congress' Federal Research Division on country studies on Chile (1992). 


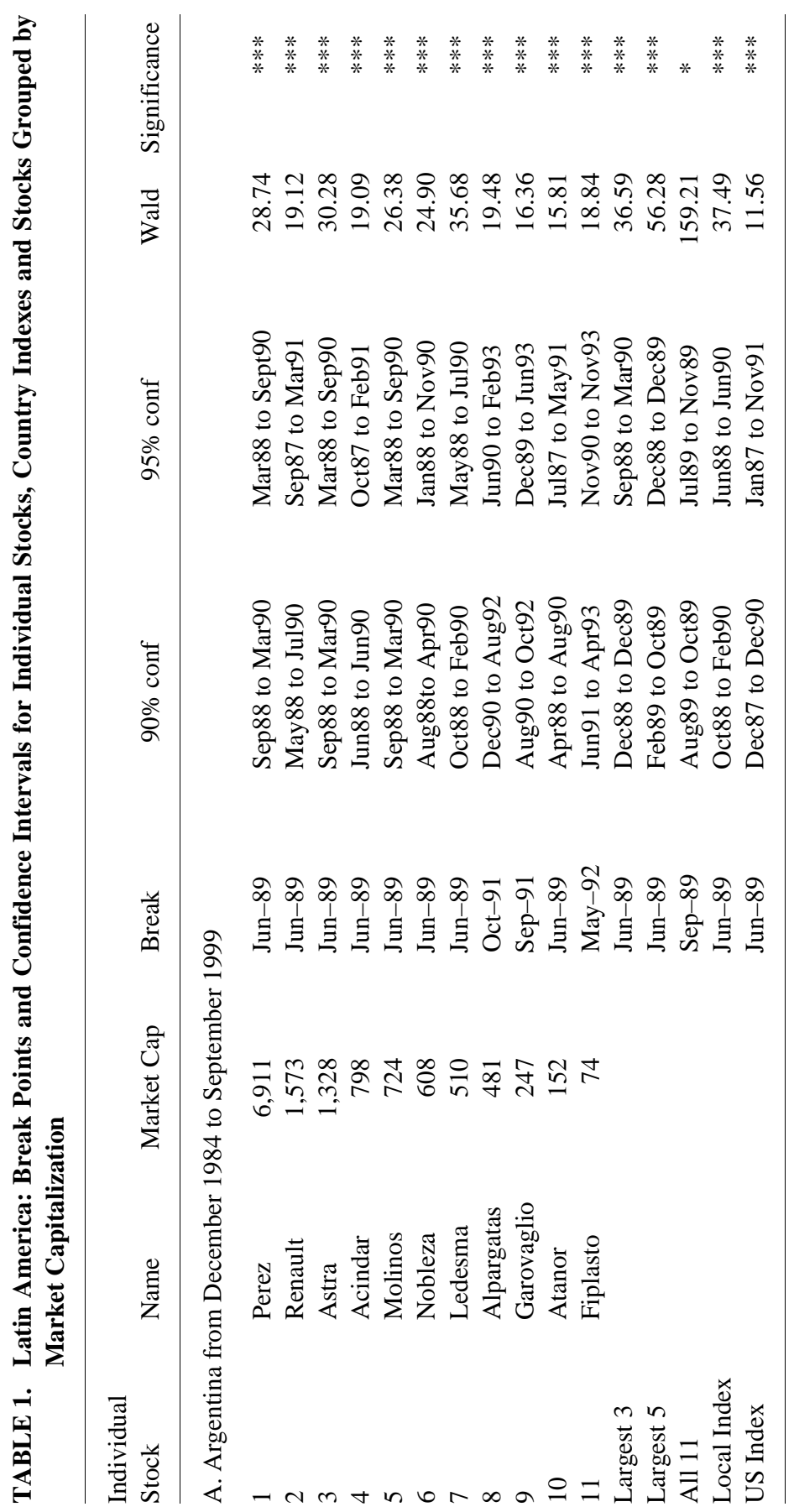




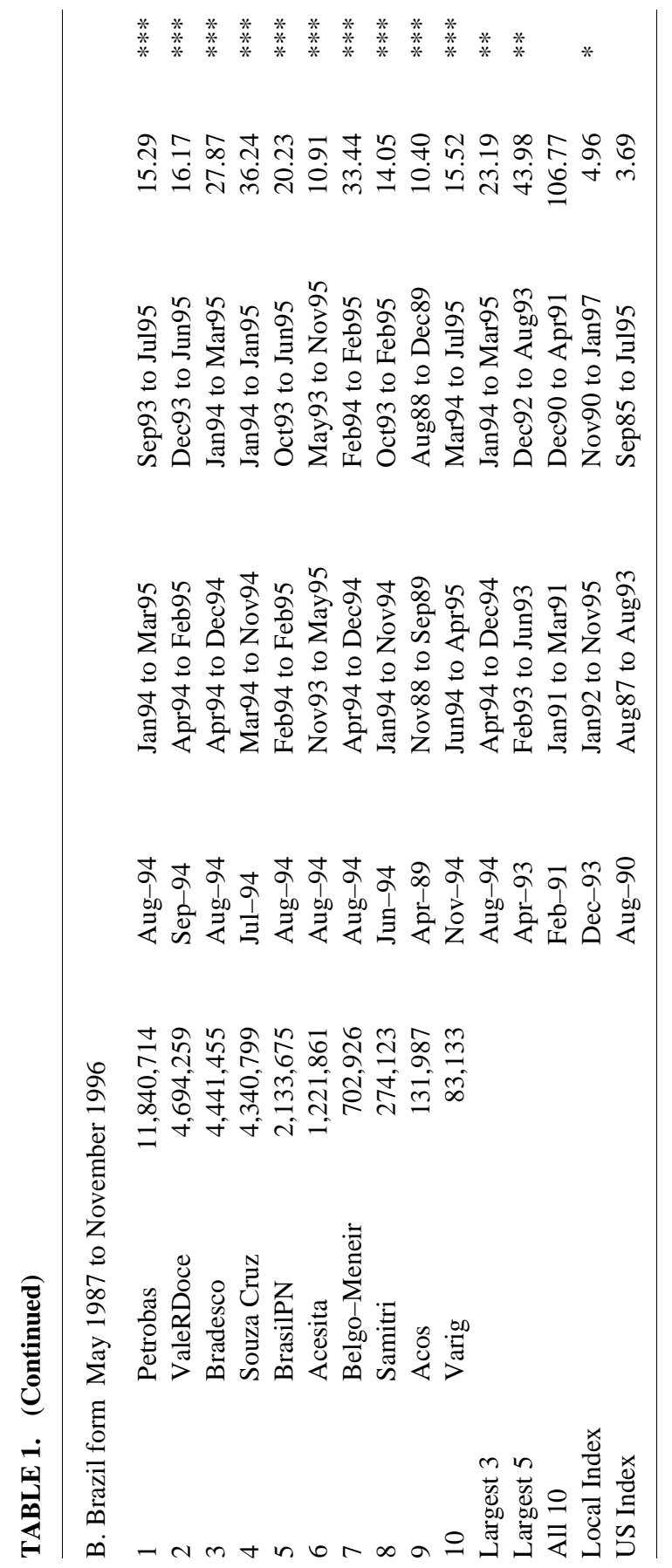




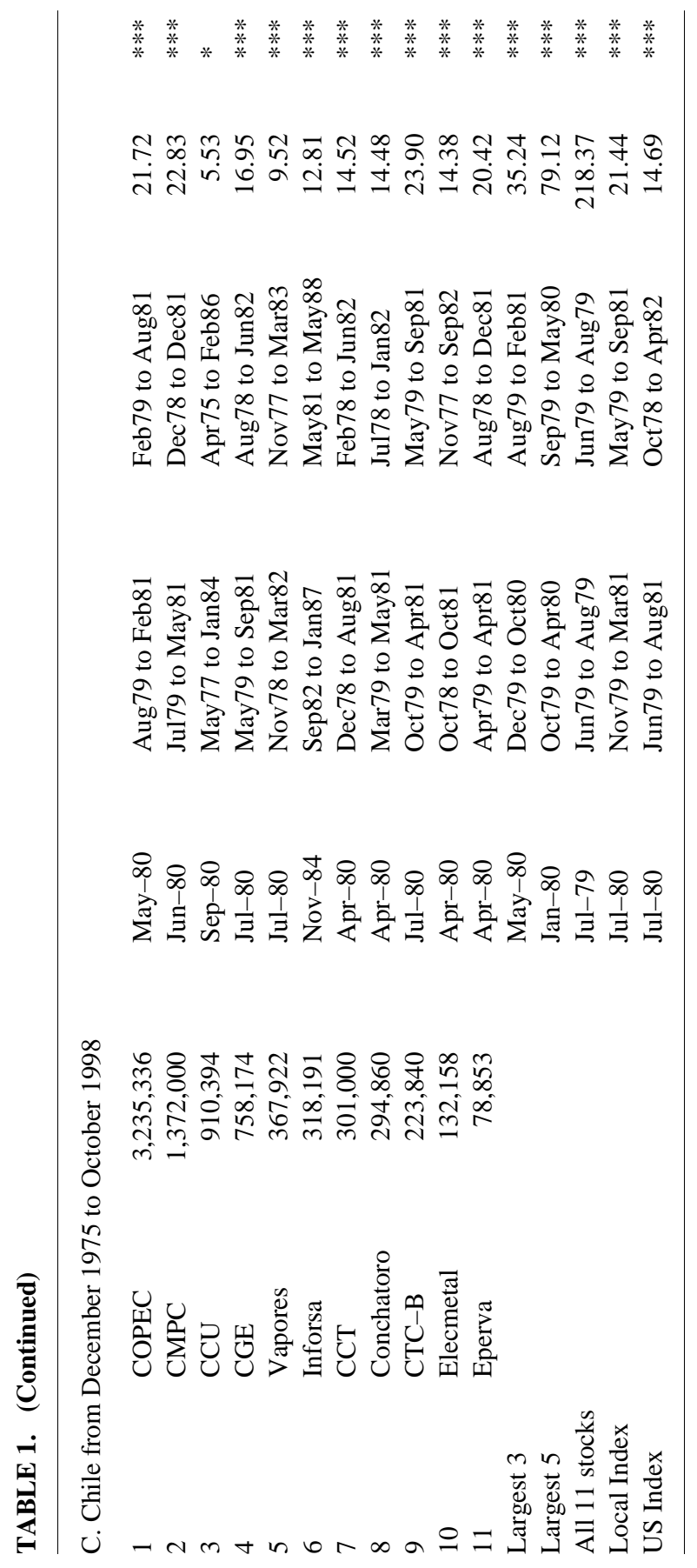




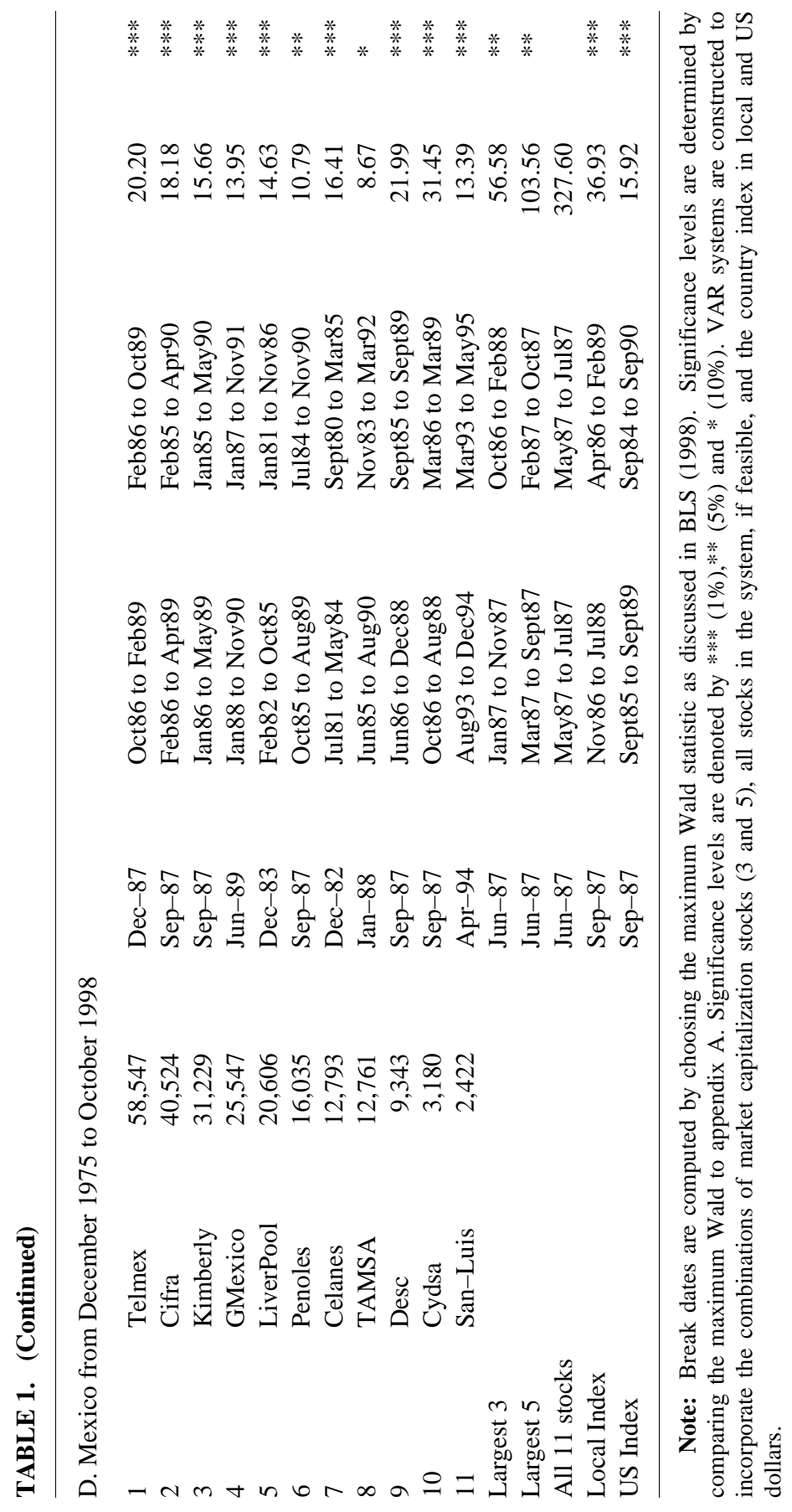


TABLE 2. Latin America: Tests for Changes in Mean Returns Pre and Post Break

\begin{tabular}{|c|c|c|c|c|}
\hline $\begin{array}{l}\text { Individ. } \\
\text { Stock }\end{array}$ & Name & Pre-Break & Post-Break & $\begin{array}{l}\text { Test Statistic } \\
U \text { post }<U \text { pre }\end{array}$ \\
\hline
\end{tabular}

A. Argentina

\begin{tabular}{|c|c|c|c|c|}
\hline 1 & Perez & 0.1266 & 0.0452 & $1.87 * *$ \\
\hline 2 & Renault & 0.1033 & 0.0297 & $1.81 * *$ \\
\hline 3 & Astra & 0.1133 & 0.0423 & $2.05^{* *}$ \\
\hline 4 & Acindar & 0.1140 & 0.0292 & $1.61^{*}$ \\
\hline 5 & Molinos & 0.1296 & 0.0346 & $1.98 * *$ \\
\hline 6 & Nobleza & 0.1076 & 0.0286 & $1.79 * *$ \\
\hline 7 & Ledesma & 0.1310 & 0.0240 & $2.52 * * *$ \\
\hline 8 & Alpargatas & 0.1115 & 0.0066 & $2.14 * *$ \\
\hline 9 & Garovaglio & 0.1121 & 0.0145 & $1.84 * *$ \\
\hline 10 & Atanor & 0.1240 & 0.0201 & $2.16^{* *}$ \\
\hline 11 & Fiplasto & 0.1125 & 0.0183 & $2.21 * *$ \\
\hline \multicolumn{5}{|c|}{ B. Brazil } \\
\hline 1 & Petrobas & 0.2309 & 0.0035 & $4.92 * * *$ \\
\hline 2 & ValeRDoce & 0.2362 & -0.0021 & $6.26 * * *$ \\
\hline 3 & Bradesco & 0.2282 & 0.0146 & $6.39 * * *$ \\
\hline 4 & Souza Cruz & 0.2239 & -0.0122 & $5.95 * * *$ \\
\hline 5 & BrasilPN & 0.2100 & -0.0400 & $5.33 * * *$ \\
\hline 6 & Acesita & 0.2153 & -0.0629 & $5.57 * * *$ \\
\hline 7 & Belgo-Meneir & 0.2168 & -0.0280 & $7.38 * * *$ \\
\hline 8 & Samitri & 0.2079 & -0.0072 & $5.15^{* * *}$ \\
\hline 9 & Acos & 0.1242 & -0.0119 & $2.29 * *$ \\
\hline 10 & Varig & 0.2010 & -0.0141 & $4.69 * * *$ \\
\hline \multicolumn{5}{|c|}{ C. Chile } \\
\hline 1 & COPEC & 0.1059 & 0.0139 & $3.85 * * *$ \\
\hline 2 & CMPC & 0.0955 & 0.0159 & $3.33 * * *$ \\
\hline 3 & $\mathrm{CCU}$ & 0.0832 & 0.0151 & $2.58 * * *$ \\
\hline 4 & CGE & 0.0905 & 0.0202 & $2.30 * *$ \\
\hline 5 & Vapores & 0.0582 & 0.0092 & $2.04 * *$ \\
\hline 6 & Inforsa & 0.0735 & 0.0016 & $2.75 * * *$ \\
\hline 7 & CCT & 0.0931 & 0.0169 & $2.37 * * *$ \\
\hline 8 & Conchatoro & 0.0772 & 0.0157 & $2.43 * * *$ \\
\hline 9 & CTC-B & 0.1403 & 0.0140 & $2.19 * *$ \\
\hline 10 & Elecmetal & 0.0794 & 0.0145 & $3.28 * * *$ \\
\hline 11 & Eperva & 0.0945 & 0.0025 & $4.29 * * *$ \\
\hline
\end{tabular}


TABLE 2. (Continued)

\begin{tabular}{|c|c|c|c|c|}
\hline 1 & Telmex & 0.0142 & 0.0335 & -1.17 \\
\hline 2 & Cifra & 0.0479 & 0.0293 & 1.17 \\
\hline 3 & Kimberly & 0.0393 & 0.0184 & 1.14 \\
\hline 4 & GMexico & 0.0418 & 0.0181 & 1.16 \\
\hline 5 & LiverPool & 0.0389 & 0.0252 & 0.80 \\
\hline 6 & Penoles & 0.0474 & 0.0174 & $1.46^{*}$ \\
\hline 7 & Celanes & 0.0475 & 0.0199 & $1.38 *$ \\
\hline 8 & TAMSA & 0.0372 & 0.0143 & 0.89 \\
\hline 9 & Desc & 0.0437 & 0.0173 & $1.27 *$ \\
\hline 10 & Cydsa & 0.0493 & 0.0016 & $2.02 * *$ \\
\hline 11 & San-Luis & 0.0619 & 0.0094 & $2.42 * * *$ \\
\hline
\end{tabular}

Note: We report mean returns for the individual stocks in each country. Test statistics reported in panels A-D measure significant changes in mean returns pre and post-break. Changes in mean returns are distributed normally and levels of rejection are standard normal

break dates consistently indicate that a regime switch took place in 1987 (see table 1D). There are a few possible explanations for this result. The Mexican Country Fund was introduced in 1981. This was followed by aggressive measures by the government towards privatization and investment reforms that helped to spur the Bolsa's trading activities. With the country fund (a vehicle for foreign investors to buy Mexican stocks) and important government reforms already underway, these efforts could have been recognized as a clear sign of the opening of the financial markets to foreigners. The liberalization events that occurred from 1981-1987 could have been sufficient to open up equity markets to foreign participation. In addition, important liberalization events that occurred in 1988 and 1989 could have been anticipated by market participants. Thus, the effects of financial integration could easily appear sooner than either the ADR introduction or the IFC official liberalization date.

Even though the individual stocks seem to break at different dates (in particular Liverpool and San Luis) the differences are not real. This is because the Wald statistics for these stocks are not monotonic and present various local maxima. The break dates we find correspond to important events in the Mexican economy, in particular the 1982 Mexican crisis and the 1994/1995 tequila effect. These effects seem to have been more important for some stocks than for others. All stocks 


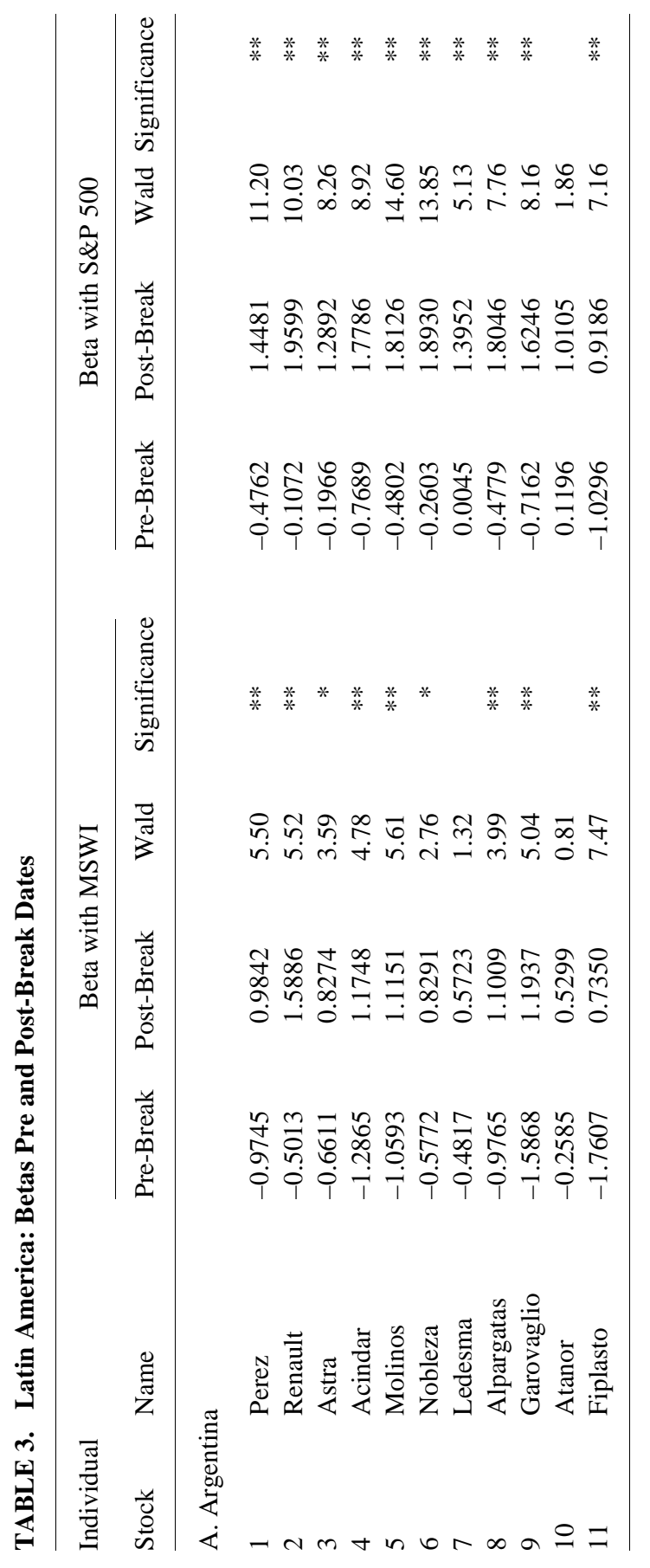




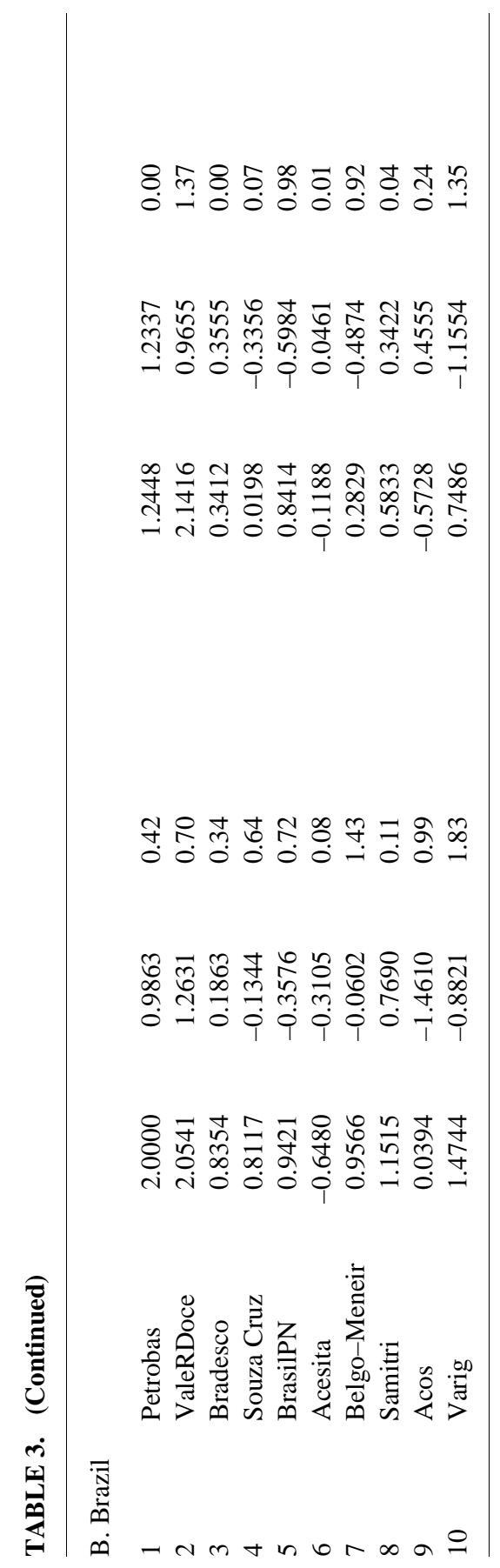




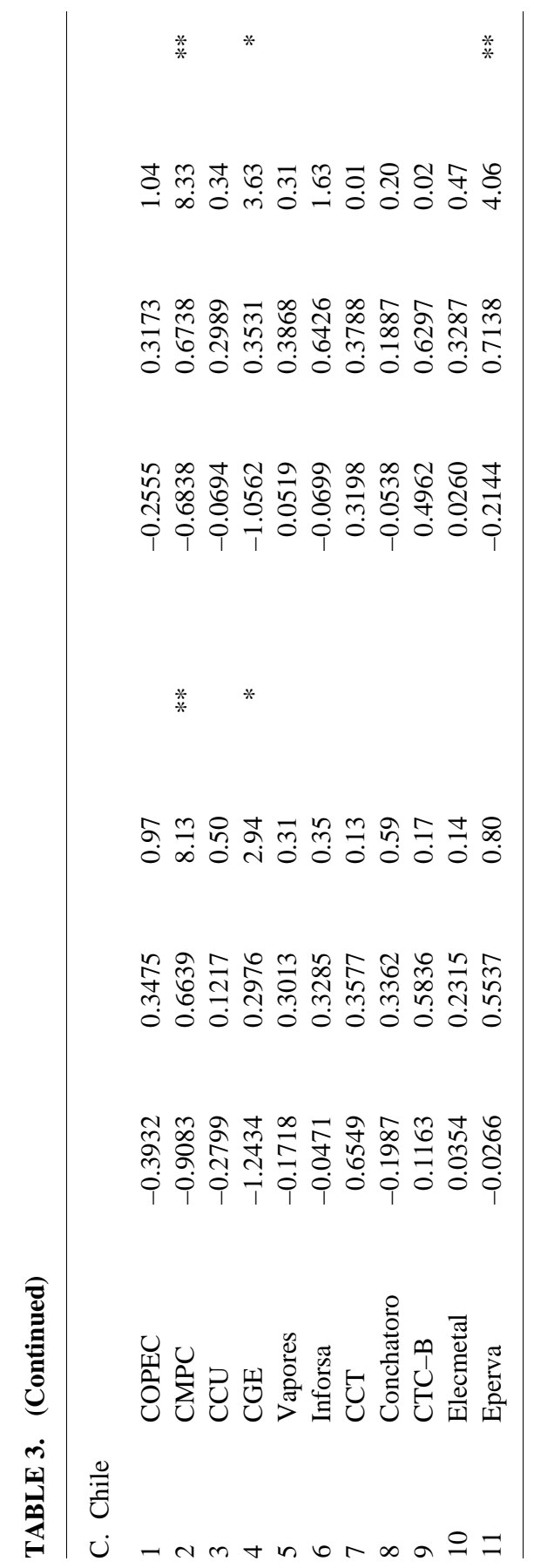




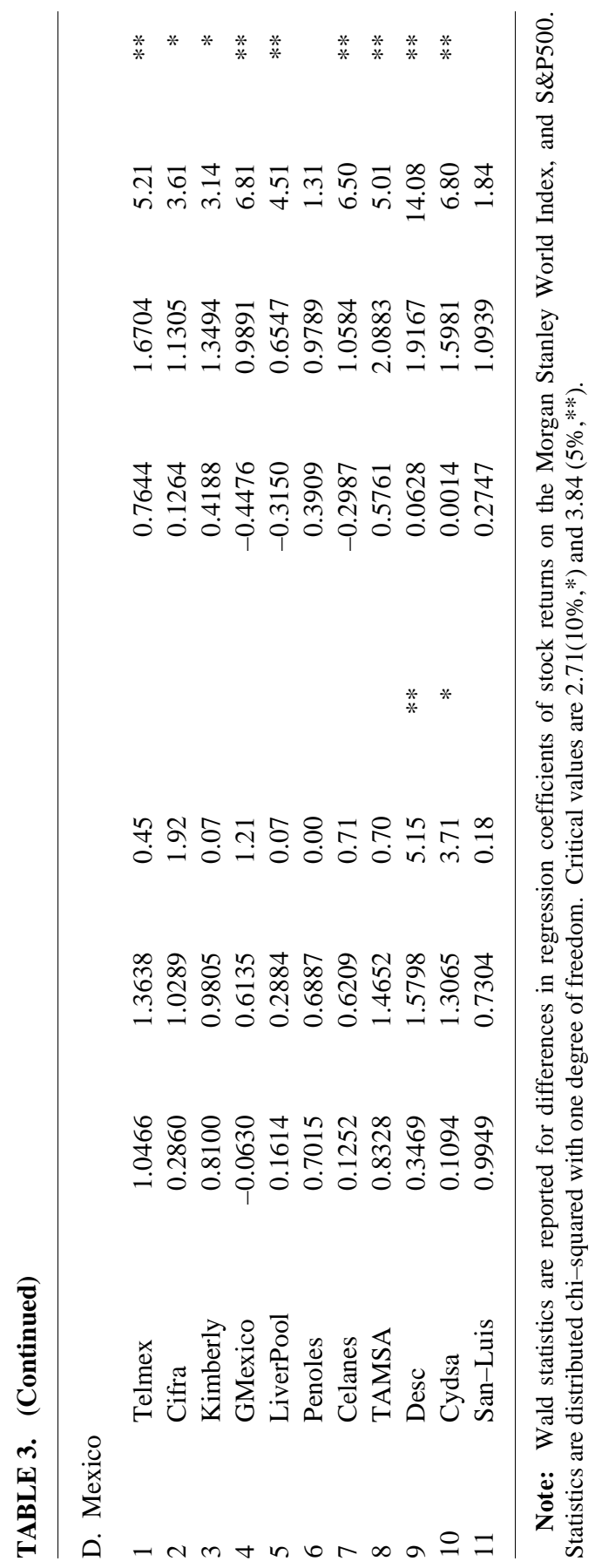


have local maxima in mid to late 1987 (our reported break date). This is confirmed by running the larger stocks in the system where we consistently find a break in June 1987.

In analyzing table $3 \mathrm{D}$, it is apparent that using the $\mathrm{S} \& \mathrm{P} 500$ produces stronger regression results than using the MSWI. Out of the 11 stocks in the sample, 9 have a significant increase in their beta with the S\&P500 post break; 7 are significant at the 5\% level and 2 at the $10 \%$ level. Three of these stocks have betas which change from negative to positive. This change in sign is an even stronger indication of financial integration than just a pure increase. Prior to integration, these stocks move in opposite direction to the US index and as they become part of the global economy, these stocks move with the whole economy as their beta becomes positive. The stronger explanatory power of the S\&P500 to the MSWI may suggest that financial integration happens with respect to the US and not with the world economy.

\section{B. South Asia}

The countries that constitute this region in the IFC database include India, Indonesia, Malaysia and Thailand. Other countries in this region were not included because they did not have sufficient data for us to perform our analysis. With the exception of Thailand, there is little evidence of financial integration among these countries.

\section{India}

India has a rapidly expanding stock market that in 1993 listed around 5,000 companies in fourteen stock exchanges, although only the stocks of about 400 of these companies were actively traded. Financial institutions and government bodies controlled an estimated 45 percent of all listed capital. In April 1992, the Bombay stock market, the nation's largest with a capital of US $\$ 65.1$ billion, collapsed, in part because of revelations about financial malpractice amounting to US $\$ 2$ billion. ${ }^{18}$ During the same time frame, India was also pursuing various liberalization policies, including the first international equity offering, first $\mathrm{ADR}$ and the relaxation of foreign investment laws pertaining to listed

18. Library of Congress' Federal Research Division on country studies on India (1995). 
Indian securities. ${ }^{19}$

Fourteen of the largest stocks are examined for the period March 1979 to December 1995. The results for 7 of the 14 stocks as well as the VAR system of the largest 3, 5 and 10 stocks all indicate a break during the early 1992 period. However, table 4A indicates that the VAR combinations yield insignificant break dates. In contrast, the individual stocks and index in local currency yield significant breaks at the $5 \%$ level.

In order to disentangle the effects of integration break versus "local crisis" during the first quarter of 1992, we more closely examine tables 5 and 6 for integration evidence. Statistics obtained in table $5 \mathrm{~A}$ provide little evidence of financial integration with regard to changes in mean returns. Further, there is no increase in beta with respect to the MSWI or S\&P500 for any of the stocks. Given the inconsistent break date results and lack of supporting statistics for financial integration, we conclude that India has not financially integrated with world stock markets.

\section{Indonesia}

Sixteen stocks for Indonesia are examined for the period December 1989 to December 1995. As shown in table 4B, the majority of our 16 Indonesian stocks break in late $1991 .{ }^{20}$ Five of the stocks that break during this time period are significant at the $1 \%$ level. The VAR system of the largest 3 and 5 stocks also produce a late 1991 break with $90 \%$ confidence intervals being reduced to 3 months on either side of the break date for the largest 3 stocks and to 1 month when we incorporate the 5 largest stocks into the system. However, the Wald test statistic is only significant at the $10 \%$ level for the largest 3 stocks and is not significant for the VAR system that incorporates the 5 largest stocks. We do not run all 16 stocks in the VAR since $15 \%$ trimming is not a sufficient amount of observations to cut in order to obtain a non-singular

19. Bekaert, Harvey, and Lumsdaine (2001) date integration for India in 1992. We find no evidence of financial integration.

20. Although not reported here, we performed our initial analysis on the full sample which included the Southeast Asian crisis of 1997. A detailed analysis of those results revealed a bimodal distribution for the Wald statistics produced in our VAR system of equations. In order to eliminate the late 1997 break due to the Asian crisis, we truncated our sample to December 1995. 
matrix. By increasing the trimming value, one obtains a monotonically decreasing function since the $k$ that yields the highest test statistic is trimmed from the sample.

Table 5B shows no difference of mean returns pre and post-break. There is only limited evidence that stock returns versus industry returns change. Examining table $6 \mathrm{~B}$, it is found that the changes in the betas with respect to the MSWI and the S\&P500 are mixed, as well as insignificant. The Wald statistics are only significant for 3 of the 16 stocks. Even though the changes in the betas for these stocks are in the right direction for integration we feel that it would be a stretch to claim that we found evidence that the break is indicative of financial integration.

The VAR results provide limited support for a break in late 1991. No significant breaks are found when stocks are grouped by market capitalization. With regard to the timeline, this period is consistent with the various liberalizations that took place in Indonesia. 1989 marked the first real opportunity for foreigners to fully participate in the Jakarta Exchange. Our break date falls in between the Country Fund introduction, Decree 1055 in 1989 and the IPO/ADR events of 1991 to 1995.

We believe the limited support for a break in our results (i.e., our beta and mean return estimates) is due to lack of data for Indonesia prebreak. In addition, insignificant beta results are consistent with the limited evidence we have from our VAR system. The lack of strong evidence for a break may indicate problems with corporate governance issues in Indonesia. Up until 1998, the Indonesian government had important influence on the economy. The resulting conflicts of interest could discourage foreign investors from participating in the country's stock markets. Lastly, Bekaert, Harvey, and Lumsdaine (2001) date integration in late 1989 for Indonesia. Although not reported here, we run separate analyses for mean returns and beta coefficients at this 1989 break date and find no evidence supporting financial integration.

Malaysia

Fifteen stocks are examined for the period December 1984 to December 1995. Given that the results obtained vary in the break dates for individual stocks, stocks grouped by market capitalization and country index, we closely analyzed Malaysia's timeline of events to pinpoint 


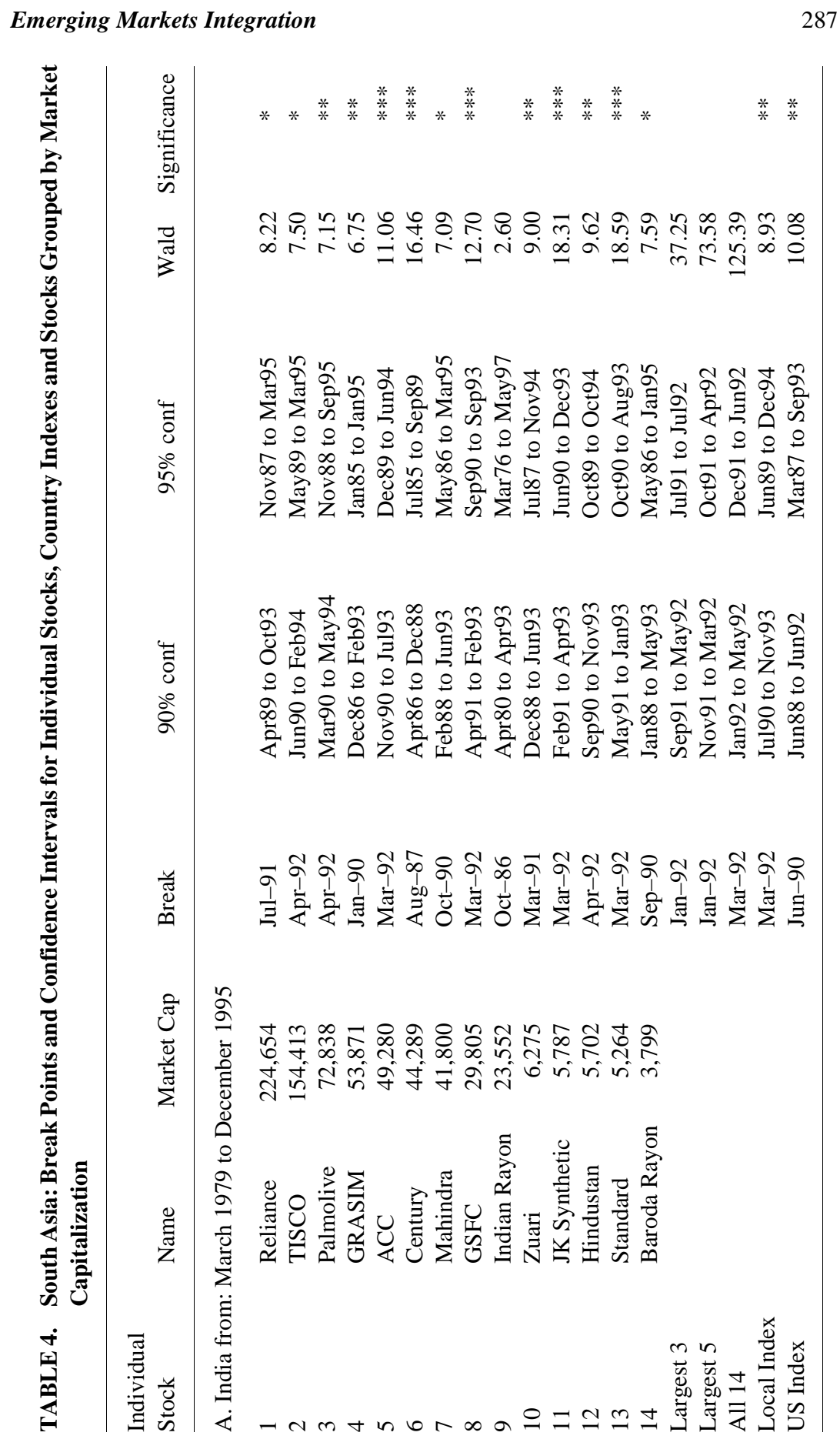




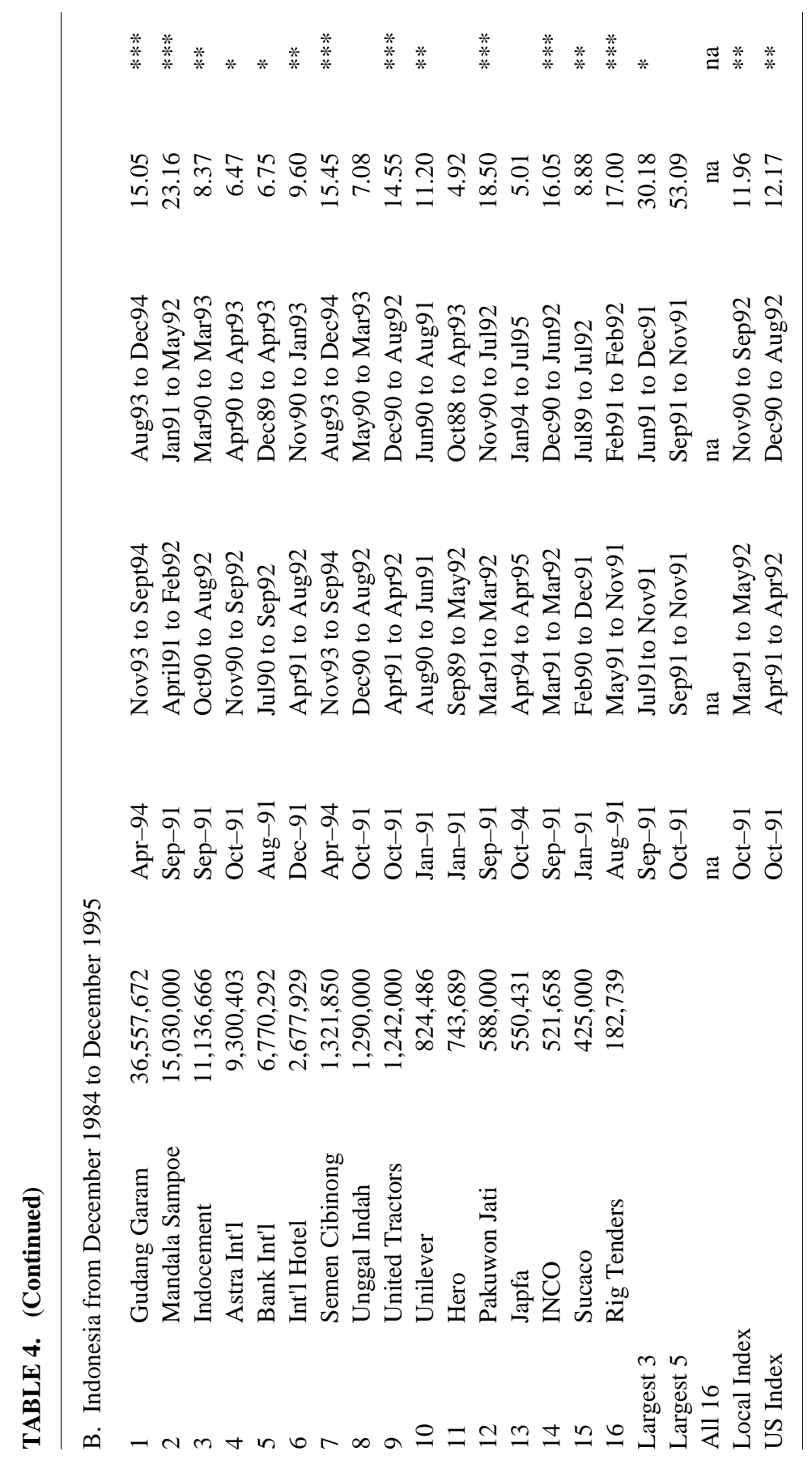




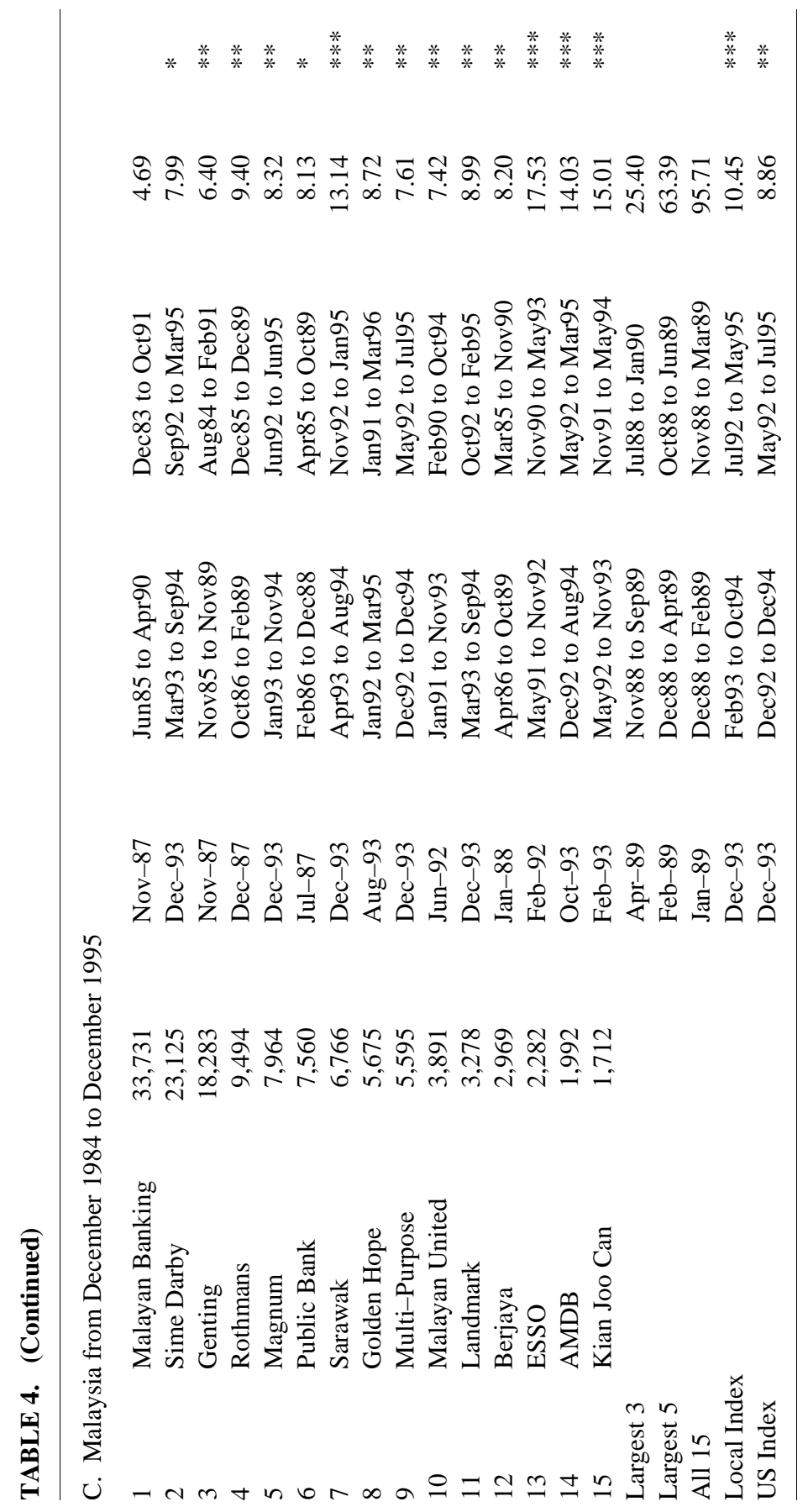




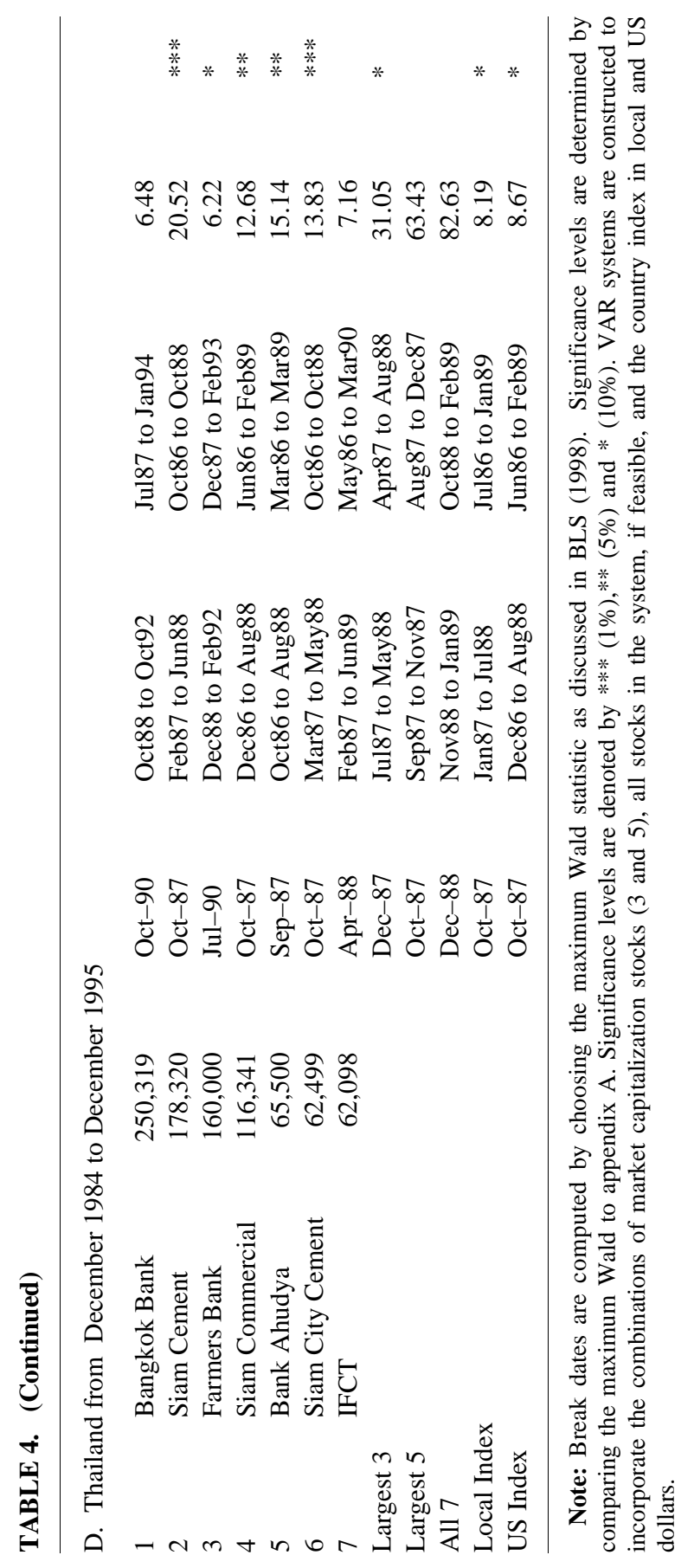


TABLE 5. South Asia: Tests for Changes in Mean Returns Pre and Post-Break

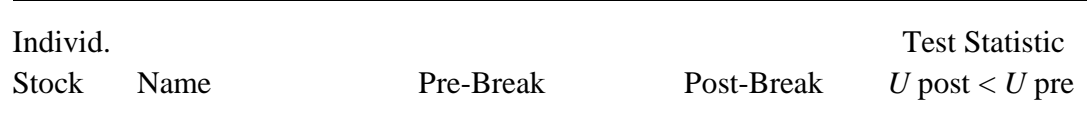

Panel A. India

\begin{tabular}{|c|c|c|c|}
\hline Reliance & 0.0128 & -0.0070 & 0.86 \\
\hline TISCO & 0.0253 & -0.0160 & $1.84 * *$ \\
\hline Palmolive & 0.0267 & 0.0090 & 1.08 \\
\hline GRASIM & 0.0128 & 0.0044 & 0.54 \\
\hline $\mathrm{ACC}$ & 0.0215 & -0.0020 & 1.11 \\
\hline Century & 0.0235 & -0.0110 & $2.19 * *$ \\
\hline Mahindra & 0.0136 & 0.0278 & -0.78 \\
\hline GSFC & 0.0185 & -0.0190 & $2.32 * *$ \\
\hline Indian Rayon & 0.0143 & 0.0072 & 0.41 \\
\hline Zuari & 0.0119 & 0.0140 & -0.08 \\
\hline JK Synthetic & 0.0022 & -0.0150 & 0.67 \\
\hline Hindustan & 0.0092 & 0.0035 & 0.26 \\
\hline Standard Industries & 0.0109 & -0.0370 & $1.89^{* *}$ \\
\hline Baroda Rayon & 0.0120 & -0.0170 & 1.19 \\
\hline \multicolumn{4}{|l|}{ Indonesia } \\
\hline Gudang Garam & -0.0058 & 0.0310 & -1.48 \\
\hline Mandala Sampoe & -0.0438 & 0.0673 & -3.30 \\
\hline Indocement & -0.0241 & 0.0102 & -1.03 \\
\hline Astra Int'1 & -0.0241 & 0.0057 & -1.09 \\
\hline Bank Int'l & -0.0255 & 0.0270 & -1.19 \\
\hline Int'l Hotel & -0.0424 & 0.0128 & -1.28 \\
\hline Semen Cibinong & -0.0511 & -0.0035 & -1.62 \\
\hline Unggal Indah & -0.0728 & 0.0005 & -1.57 \\
\hline United Tractors & -0.0045 & 0.0060 & -0.37 \\
\hline Unilever & -0.0296 & 0.0126 & -1.14 \\
\hline Hero & 0.0083 & 0.0125 & -0.09 \\
\hline Pakuwon Jati & -0.0099 & -0.0033 & -0.20 \\
\hline Japfa & -0.0133 & -0.0166 & 0.09 \\
\hline INCO & -0.0238 & -0.0044 & -0.74 \\
\hline Sucaco & -0.0404 & -0.0184 & -0.35 \\
\hline Rig Tenders & -0.0505 & 0.0005 & 1.69 \\
\hline \multicolumn{4}{|l|}{ Malaysia } \\
\hline Malayan Banking & -0.0001 & 0.0257 & -1.09 \\
\hline Sime Darby & 0.0136 & 0.0104 & 0.16 \\
\hline Genting & 0.0019 & 0.0259 & -1.08 \\
\hline
\end{tabular}


TABLE 5. (Continued)

\begin{tabular}{lcrrr}
\hline 4 & Rothmans & 0.0050 & 0.0176 & -0.51 \\
5 & Magnum & -0.0075 & 0.0249 & -1.60 \\
6 & Public Bank & 0.0036 & 0.0078 & -0.17 \\
7 & Sarawak & 0.0005 & 0.0108 & -0.41 \\
8 & Golden Hope & 0.0131 & 0.0054 & 0.32 \\
9 & Multi-Purpose & -0.0056 & 0.0115 & -0.56 \\
10 & Malayan United & -0.0032 & 0.0045 & -0.29 \\
11 & Landmark & -0.0351 & 0.0068 & -1.15 \\
12 & Berjaya & -0.0149 & 0.0037 & -0.63 \\
13 & ESSO & 0.0108 & 0.0037 & 0.56 \\
14 & AMDB & -0.0030 & 0.0060 & -0.37 \\
15 & Kian Joo Can & -0.0046 & 0.0272 & -1.68 \\
& & & & \\
D. Thailand & & & -0.51 \\
1 & Bangkok Bank & 0.0153 & 0.0223 & -0.02 \\
2 & Siam Cement & 0.0241 & 0.0245 & -0.02 \\
3 & Farmers Bank & 0.0222 & 0.0225 & -0.06 \\
4 & Siam Commercial & 0.0207 & 0.0219 & 1.04 \\
5 & Bank Ahudya & 0.0337 & 0.0164 & $1.56^{*}$ \\
6 & Siam City & 0.0459 & 0.0155 & -0.57 \\
7 & IFCT & 0.0067 & 0.0169 & $T$ \\
\hline
\end{tabular}

Note: We report mean returns for the individual stocks in each country. Test statistics reported in panels A-D measure significant changes in mean returns pre and post-break. Changes in mean returns are distributed normally and levels of rejection are standard normal critical values. Significance levels are denoted by $* * *(1 \%), * *(5 \%)$ and * $(10 \%)$.

potential integration dates. First, break dates for individual stocks seem to fall into 2 groups: (1) late 1987 and (2) late 1993. Malaysia's country fund was introduced in December 1987, which could very well explain this first break date. In late 1992, the Malaysian government approved the formation of a SEC. In early 1993, Malaysia lifted its 30\% limit on foreign ownership of manufacturing firms. In addition, October 1993 witnessed the resignation of the deputy prime minister. Given that the country index breaks significantly in December 1993, it is probable that one or a combination of these events could be the cause for the break in late 1993.

The largest 5 and 10 stocks yield a break date in early 1989, although 


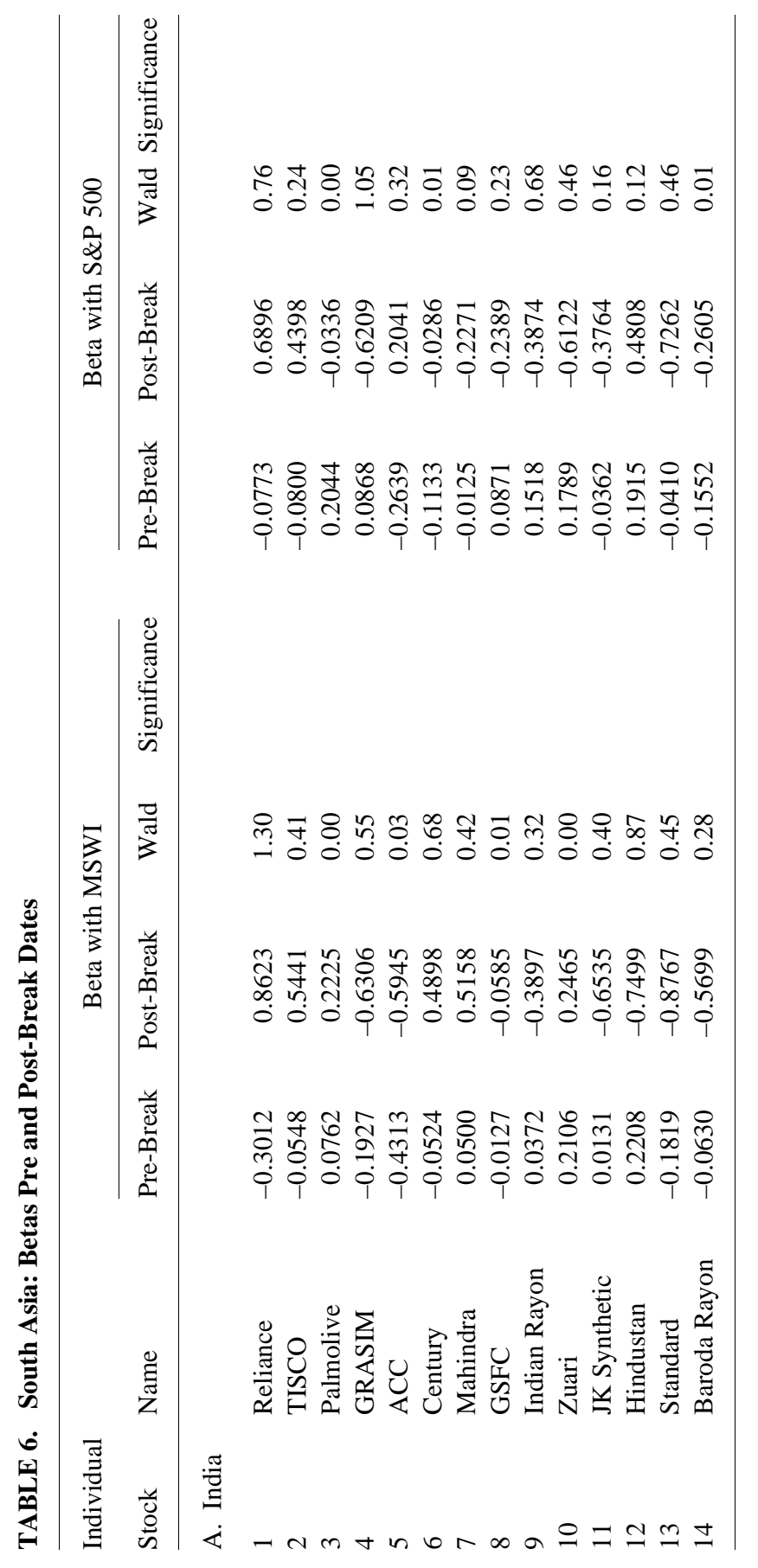




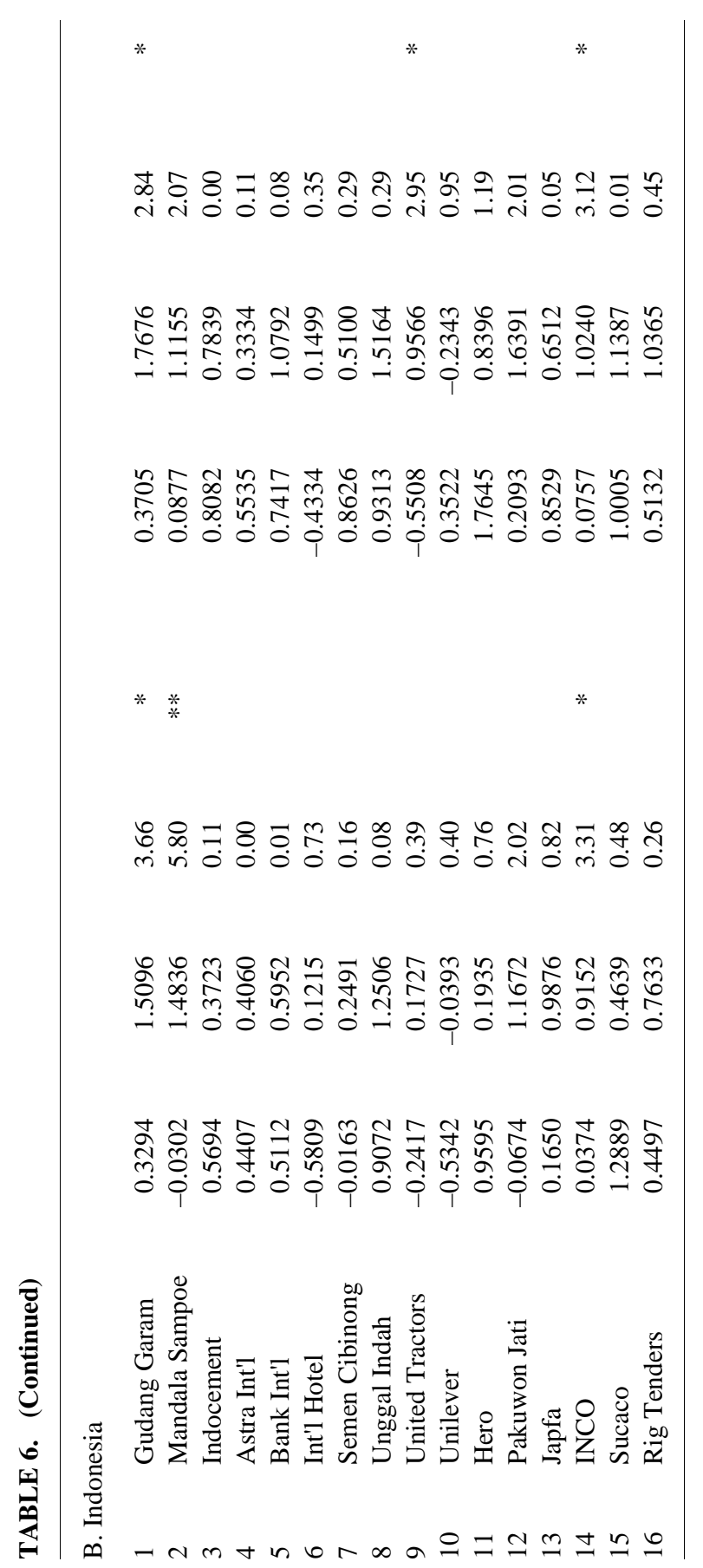




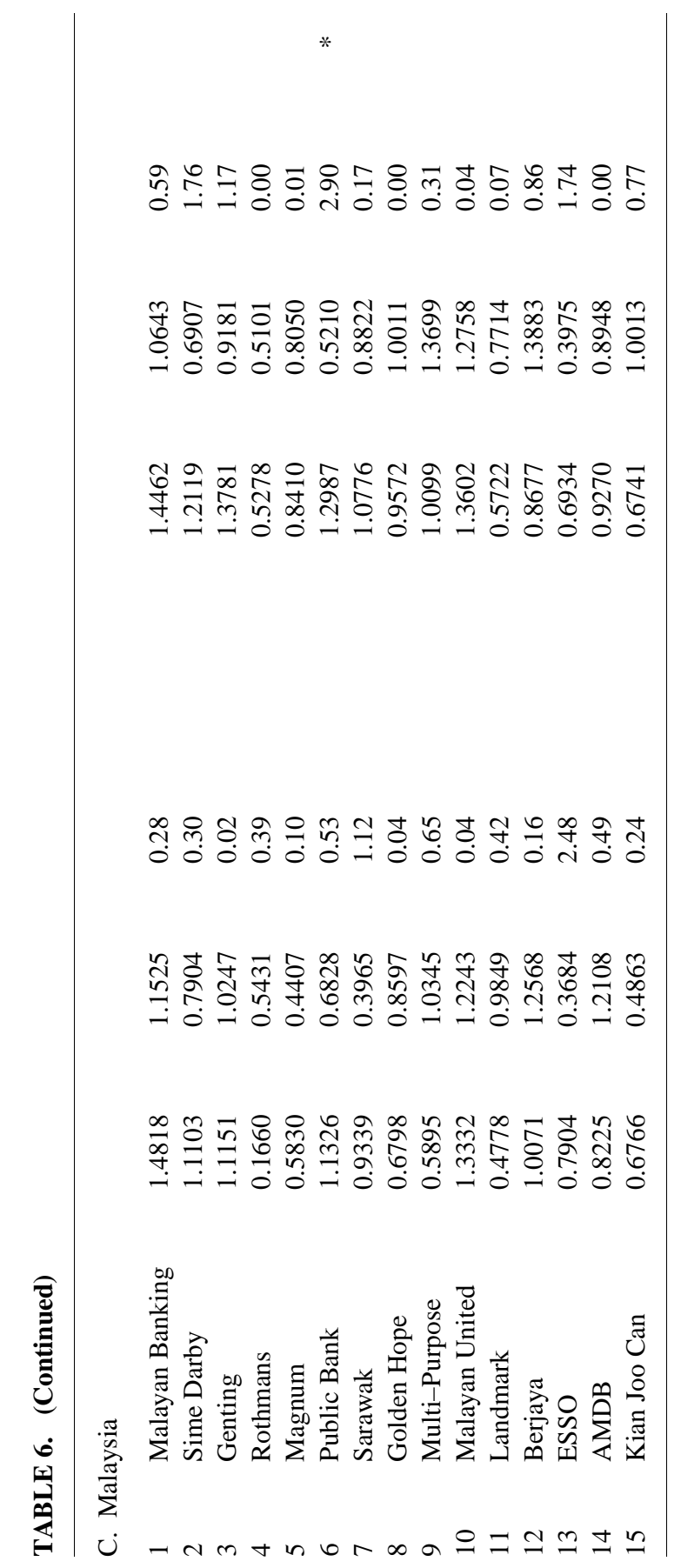




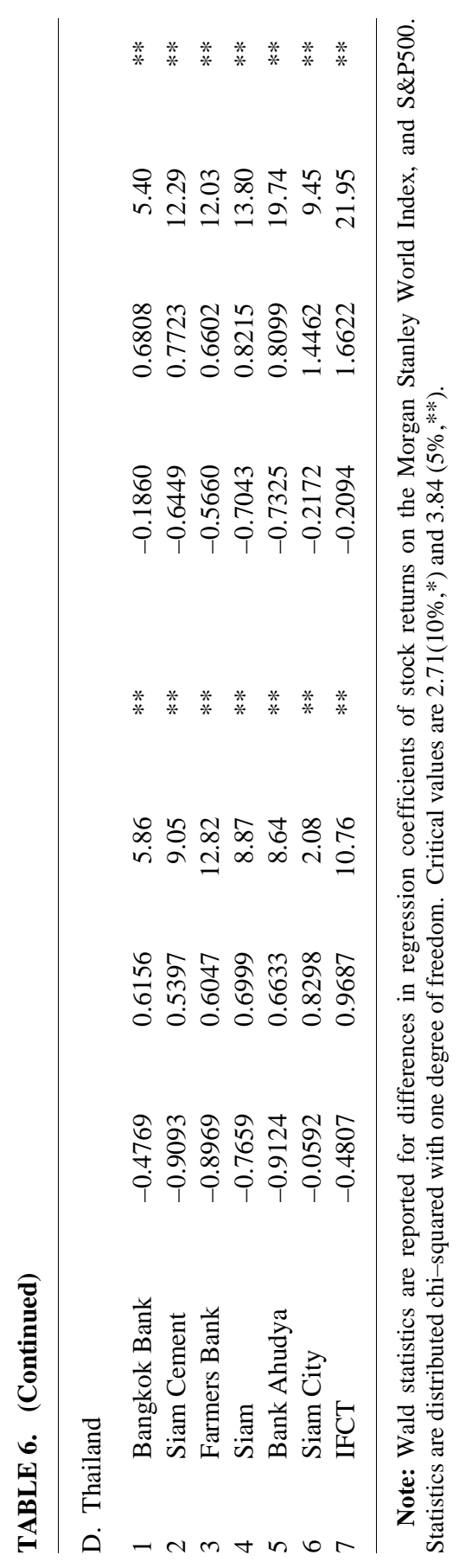


these breaks are insignificant at all levels. Despite this result, the events in Malaysia would best support a break in this period. The previous year was marked by (1) the country fund introduction; (2) a budget calling for the liberalization of foreign ownership policy; and (3) declaration of market openness by the IFC. Unfortunately tables 5C and 6C do not support early 1989 as the integration period. There are no significant changes in mean returns and no increases in beta coefficients with the benchmark indexes for any of the stocks pre and post-break. ${ }^{21}$ We therefore conclude that Malaysia is not fully financially integrated into world markets.

\section{Thailand}

Thailand is the only country in the South Asia sample that produces results supporting financial integration. Seven of Thailand's largest stocks are examined for the period December 1984 to December 1995. Five of the seven stocks in the sample, the VAR system of 5 largest stocks and the country index in both local and US currency result in a break date corresponding to late 1987.

With the launch of the Thai fund in late 1986 and the inauguration of the Alien Board in late 1987, our break date seems to make sense. Bekaert, Harvey, and Lumsdaine (2001) have claimed that financial integration occurred one year later for Thailand but we find no evidence to support this claim. Strong evidence for a break in late 1987 is shown in table 6D. All stocks exhibit significant increases in their beta coefficients with the MSWI, S\&P500 as well as industry indexes at the $5 \%$ level.

\section{Conclusions}

In this study, we attempt to identify break dates of emerging financial markets and more importantly to confirm whether econometric breaks are indicative of financial integration. A two-step process is used to accomplish these tasks. First, the econometric techniques discussed previously are utilized to identify significant breaks in the return series

21. Although not reported, we checked these statistics for the December 1987 and December 1993 break dates and obtained insignificant results as well. 
for a sample of 8 emerging market countries. The major contribution at this phase of the analysis is that we use multiple stock return series per country: adding additional time series to the VAR system results in a narrower confidence interval, thus providing a more informative statistic for the identification of break dates. Second, we provide supporting evidence that these break dates, which differ in some cases from past studies, represent integration periods by looking at various statistical properties of the return distribution. The statistical evidence provided are changes in mean returns and correlation coefficients pre and postbreak date.

Our main conclusion is that even though we may find significant break dates in our sample of emerging economies' return series, not all breaks are attributable to financial integration. In many of these countries, events such as currency crises cause drastic changes in return series without affecting the integration of the emerging market. In this study, the evidence supports integration in the majority of Latin American markets in our sample but not in the Asian markets examined. We conjecture that the difference in the way privatizations were carried out in Asia and Latin America may account for these findings. Much care was taken in Latin America when privatizations took place to provide control to private owners and to ensure that industries being privatized were properly regulated. In general, ownership of Asian companies was transferred to private parties but was concentrated in the hands of a few individuals with close affiliation to the local governments. This structure provided few guarantees of "fairness" to foreign investors as minority shareholders. Thus, opening up Asian markets to foreigners did not necessarily imply that foreign capital participated in all sectors of the economy.

Further studies in this area should address the identification of multiple breaks in multiple series. For instance, in the case of Indonesia, we truncated our sample in order to avoid identifying the 1997 Asian crisis. Tracing the evolution of changes in pricing regimes with respect to the political, economic and financial events of emerging markets could prove to be a useful venue for future research. In particular, we may better explain the events for countries that switch between integration and segmentation, taking special care to analyze other economic events in between which are not attributable to either process. 
Appendix: Asymptotic Critical Values for $\max F(k)$ Test Statistic

\begin{tabular}{|c|c|c|c|c|}
\hline Dimension $(q)$ & $15 \%$ & $10 \%$ & $5 \%$ & $1 \%$ \\
\hline 1 & 2.04 & 2.69 & 3.88 & 6.81 \\
\hline 2 & 3.78 & 4.59 & 5.96 & 9.02 \\
\hline 3 & 5.19 & 6.12 & 7.62 & 11.04 \\
\hline 4 & 6.71 & 7.72 & 9.39 & 13.19 \\
\hline 5 & 8.13 & 9.27 & 11.14 & 15.20 \\
\hline 6 & 9.37 & 10.60 & 12.66 & 17.05 \\
\hline 7 & 10.81 & 12.10 & 14.15 & 18.53 \\
\hline 8 & 11.93 & 13.23 & 15.39 & 20.01 \\
\hline 9 & 13.42 & 14.83 & 17.07 & 21.82 \\
\hline 10 & 14.48 & 15.90 & 18.22 & 23.12 \\
\hline 11 & 15.76 & 17.27 & 19.66 & 24.60 \\
\hline 12 & 17.14 & 18.73 & 21.21 & 26.19 \\
\hline 13 & 18.15 & 19.72 & 22.17 & 27.18 \\
\hline 14 & 19.40 & 21.00 & 23.51 & 28.95 \\
\hline 15 & 20.60 & 22.30 & 25.01 & 30.57 \\
\hline 16 & 21.72 & 23.43 & 26.14 & 31.58 \\
\hline 17 & 22.99 & 24.82 & 27.70 & 33.64 \\
\hline 18 & 24.11 & 25.92 & 28.74 & 34.76 \\
\hline 19 & 25.23 & 27.10 & 29.94 & 35.86 \\
\hline 20 & 26.54 & 28.47 & 31.47 & 37.69 \\
\hline 21 & 27.70 & 29.67 & 32.77 & 38.92 \\
\hline 22 & 28.60 & 30.56 & 33.61 & 39.73 \\
\hline 23 & 29.86 & 31.83 & 34.90 & 41.40 \\
\hline 24 & 31.33 & 33.42 & 36.74 & 43.40 \\
\hline 25 & 32.13 & 34.22 & 37.46 & 43.87 \\
\hline 26 & 33.53 & 35.73 & 39.15 & 45.83 \\
\hline 27 & 34.36 & 36.56 & 39.87 & 46.72 \\
\hline 28 & 35.62 & 37.81 & 41.18 & 48.12 \\
\hline 29 & 36.89 & 39.11 & 42.48 & 49.14 \\
\hline 30 & 37.77 & 40.01 & 43.47 & 50.48 \\
\hline 31 & 39.06 & 41.31 & 44.78 & 52.05 \\
\hline 32 & 39.98 & 42.30 & 45.90 & 53.09 \\
\hline 33 & 41.21 & 43.57 & 47.24 & 54.61 \\
\hline 34 & 42.16 & 44.58 & 48.35 & 56.03 \\
\hline 35 & 43.80 & 46.21 & 49.90 & 57.63 \\
\hline 36 & 44.75 & 47.26 & 51.01 & 58.44 \\
\hline 37 & 45.73 & 48.17 & 51.95 & 59.50 \\
\hline 38 & 46.85 & 49.42 & 53.43 & 61.30 \\
\hline 39 & 48.02 & 50.53 & 54.31 & 62.02 \\
\hline 40 & 49.20 & 51.75 & 55.71 & 63.71 \\
\hline 41 & 50.25 & 52.90 & 56.95 & 65.20 \\
\hline 42 & 51.36 & 53.99 & 58.04 & 65.97 \\
\hline 43 & 52.67 & 55.27 & 59.36 & 67.72 \\
\hline 44 & 53.76 & 56.48 & 60.61 & 69.11 \\
\hline 45 & 55.06 & 57.79 & 61.94 & 70.35 \\
\hline 46 & 55.90 & 58.67 & 62.90 & 71.67 \\
\hline 47 & 56.90 & 59.66 & 63.87 & 72.28 \\
\hline 48 & 57.88 & 60.60 & 64.80 & 73.43 \\
\hline 49 & 59.25 & 62.12 & 66.48 & 75.14 \\
\hline 50 & 60.41 & 63.32 & 67.73 & 76.13 \\
\hline
\end{tabular}

Note: Generated using $F^{*}(\tau)=\{\tau(1-\tau)\}^{-1}(W(\tau)-\tau W(1))^{2}$. Values for $q$ greater than 50 available upon request. 


\section{References}

Ammer, J., and Mei, J. 1996. Measuring international economic linkages with stock market data. Journal of Finance 51: 1743-1763.

Andrews, D. W. K. 1993. Tests for parameter instability and structural change with unknown change point. Econometrica 61: 821-856.

Andrews, D. W. K.; Lee, I.; and Ploberger, W. 1996. Optimal changepoint tests for normal linear regression. Journal of Econometrics 70: 9-38.

Andrews, D. W. K., and Ploberger, W. 1994. Optimal tests when a nuisance parameter is present only under the alternative. Econometrica 62: 1383-1414.

Bai, J. 1992. Estimation of structural change in econometric models. Unpublished Ph.D. dissertation. Berkeley: University of California.

Bai, J. 1994. Least squares estimation of a shift in linear processes. Journal of Time Series Analysis 15: 453-472.

Bai, J.; Lumsdaine, R.L.; and Stock, J.H. 1998. Testing for and dating common breaks in multivariate time series. Review of Economic Studies 65: 395-432.

Banarjee, A.; Lumsdaine, R. L.; and Stock, J. H. 1992. Recursive and sequential tests of the unit root and trend break hypotheses: Theory and international evidence. Journal of Business and Economic Statistics 10: 271-288.

Bekaert, G., and Harvey, C.R. 1997. Foreign speculators and emerging equity markets. NBER working paper no. 6312. Cambridge, Mass.: National Bureau of Economic Research.

Bekaert, G., and Harvey, C.R. 1995. Time-varying world market integration. Journal of Finance 50: 403-444.

Bekaert, G.; Harvey, C.R.; and Lumsdaine, R.L. 2001. Dating the integration of world equity markets. Working paper. Stanford University, Duke University, and Brown University.

Bekaert, G.; Harvey, C.R.; and Lumsdaine, R.L. 1999. The dynamics of emerging market equity flows. Working paper. Stanford University, Duke University, and Brown University.

Buckberg, E. 1995. Emerging stock markets and international asset pricing. World Bank Economic Review 9: 51-74.

Campos, J.; Ericcson, N. R.; and Hendry, D. 1996. Cointegration tests in the presence of structural breaks. Journal of Econometrics 70: 187-220.

Campbell, J., and Hamao, Y. 1992. Predictable stock returns in the United States and Japan: A study of long term capital market integration. Journal of Finance 47: 43-69.

Christiano, L. J. 1992. Searching for a break in GNP. Journal of Business and Economic Statistics 10: 237-250.

Dickey, D. A., and Fuller, W. A. 1979. Distribution of the estimators for autoregressive time series with a unit root. Journal of the American Statistical Association 74: 427-431.

Domowitz, G.; Glen, J.; and Madhavan, A. 1997. Market segmentation and stock 
prices: Evidence from an emerging market. Journal of Finance 52: 1059-1085. Emerging Stock Market Facts Book. 1997. Washington DC: International Finance Corporation.

Engle, R. F., and Granger, C. W. 1987. Cointegration and error correction: Representation, estimation, and testing. Econometrica 55: 251-276.

Errunza, V., and Losq, E. 1985. International asset pricing under mild segmentation: Theory and test. Journal of Finance 40: 105-116.

Eun, C.S., and Shim, S. 1989. International transmission of stock market movements. Journal of Financial and Quantitative Analysis 24: 241-256.

Fama, E. F., and French, K. R. 1997. Industry costs of equity. Journal of Financial Economics 43: 153-193.

Gregory, A.W., and Hansen, B. E. 1996. Residual-based tests for cointegration in models with regime shifts. Journal of Econometrics 70: 99-126.

Hansen, B. E. 1992. Testing for parameter instability in regressions with I(1) processes. Journal of Business and Economic Statistics 10: 321-336.

Mitto, U. 1992. Additional evidence on integration in the Canadian stock market. Journal of Finance 47: 2035-2054.

Perron, P. 1989. The great crash, the oil price shock and the unit root hypothesis. Econometrica 57: 1361-1401.

Phillips, P. C. B. 1991. Optimal inference in cointegrated systems. Econometrica 59: 283-306.

Picard, D. 1985. Testing and estimating change-points in time series. Advances in Applied Probability 176: 841-867.

Pieper, P., and Vogel, R. 1997. Stock market integration in Latin America. Working paper. Cambridge, Mass: Harvard Institute for International Development.

Quandt, R. E. 1960. Tests of the hypothesis that a linear regression system obeys two separate regimes. Journal of the American Statistical Association 55: 324-330.

Rappaport, P., and Reichlin, L. 1989. Segmented trends and non-stationary time series. Economic Journal 99: 168-177.

Stehle, R. 1977. An empirical test of the alternative hypothesis of national and international pricing of risky assets. Journal of Finance 32: 493-502.

Stock, J. H. 1994. Unit roots, structural breaks, and trends. In R. Engle and D. McFadden (eds). Handbook of Econometrics, Volume IV. Amsterdam: Elsevier.

Vogelsang, T. and Perron, P. 1998. Additional tests for a unit root allowing for a break in the trend function at an unknown time. International Economic Review 39: 1073-11. 